\title{
NEUROARTROPATÍA DE CHARCOT
}

\section{CHARCOT NEUROARTHROPATHY}

Natalia Soledad Bertollo'

Marta Calvagno

\section{INTRODUCCIÓN}

La neuroartropatía de Charcot (NC) es un síndrome asociado con polineuropatía diabética (PND), caracterizado por fragmentación y destrucción ósea y articular que puede conducir a severas deformidades e incluso la amputación ${ }^{4-6}$. Es una artropatía relativamente dolorosa, progresiva, degenerativa, de una o múltiples articulaciones, causada por un déficit neurológico subyacente $e^{5,7}$.

En 1868 Jean-Martín Charcot describió, por primera vez, esta enfermedad en los pacientes con tabes dorsal como la "artropatía de los atáxicos" El primer caso reportado en la literatura de neuroartropatía en un paciente con diabetes data del año $1936^{10}$. La diabetes es en la actualidad la causa más frecuente de neuroartropatía, 10,11,12.

El objetivo de esta revisión es proporcionar una visión general de la neuroartropatía de Charcot en términos de patogénesis, clasificación, presentación clínica, diagnóstico y tratamiento, con especial énfasis en los nuevos conceptos sobre patogenia y tratamiento.

\section{Epidemiología}

Esta enfermedad se desarrollará en aproximadamente 1 de cada 600 pacientes con diabetes, y en 1 de cada 100 pacientes con diabetes y neuropatía ${ }^{17}$. Puede ser fácilmente pasada por alto por los no especialistas, sobre todo en las primeras etapas,

\footnotetext{
1 Staff del Servicio de Clínica Médica, Instructora de Residentes, Servicio de Clínica Médica del Sanatorio Los Alerces

${ }^{2}$ Mentora

Contacto del autor: Natalia Bertollo

E-mail: nataliabertollo@gmail.com

Correspondencia: San Juan 3034, Rosario, Santa Fe (CP0341), Argentina. Tel.: 4107000

Fecha de trabajo recibido: 22/6/14

Fecha de trabajo aceptado: 24/6/14
}

llevando a subestimar su frecuencia. Por lo tanto, su verdadera prevalencia e incidencia son desconocidas, pero se estima que afecta a $0,1-7,5 \%$ de la población diabética ${ }^{18}$. Aunque los estudios prospectivos son limitados, las tasas de incidencia reportadas van del 3 al 11,7/1.000 pacientes año ${ }^{21}$.

Es importante destacar que se ha reportado un aumento de la tasa de incidencia de NC. Este aumento se debería tanto a la mejoría en el diagnóstico apoyado por los nuevos métodos de diagnóstico por imágenes y a la menor tasa de ingresos hospitalarios, menor número de amputaciones y al creciente número de pacientes diabéticos con úlceras de pie tratados como pacientes ambulatorios con movilización temprana ${ }^{15,22}$.

Los pacientes con NC se encuentran, en su mayoría, entre la quinta y sexta década de su vida, y el $80 \%$ tiene DM de por lo menos 10 años de evolución ${ }^{15}$. Aunque puede verse también en pacientes más jóvenes de entre 20 y 30 años, generalmente diabéticos tipo 1, con al menos 10 años de evolución de su patología.

La parte media del pie y el tobillo son las articulaciones más afectadas en los pacientes diabéti$\cos ^{23}$. La forma bilateral se ha informado hasta en el $9 \%$ de los pacientes con NC aguda ${ }^{24}$. En revisiones de pacientes con enfermedad bilateral, en promedio, el tiempo de aparición de alguna lesión en el segundo pie es de dos años, la presentación de forma simultánea es infrecuente y sólo ocurre en el $0,8 \%$ de los pacientes ${ }^{26}$.

La prevalencia de la NC no difiere entre hombres y mujeres, pero se han reportado diferencias entre pacientes con diabetes mellitus tipo 1 (DM1) y diabetes mellitus tipo 2 (DM2). Recientemente se ha notado una mayor preponderancia en los pacientes con DM1 con respecto a los $\mathrm{DM} 2^{13}$.

La presentación clínica de la NC no muestra diferencias entre los pacientes con diabetes DM1 
y DM2, pero a nivel epidemiológico la edad de presentación de la NC aguda está en relación a una edad más temprana y de mayor duración de la diabetes entre los pacientes con DM120,27.

Curiosamente la enfermedad arterial periférica aparece como factor protector para el desarrollo de $\mathrm{NC}^{22}$. Esto se debe probablemente al desarrollo de una respuesta inflamatoria limitada como resultado de la isquemia ${ }^{20}$.

\section{Etiología}

La etiología y fisiopatología de esta devastadora enfermedad constituyen, actualmente, el tema central de muchos estudios. Una variedad de causas son responsables de la activación, amplificación y perpetuación de la respuesta inflamatoria que parece ser hoy el principal proceso etiopatogéni$\mathrm{CO}^{28}$. Existen firmes pruebas de que las citoquinas proinflamatorias, especialmente el complejo formado por el receptor activador del factor nuclear $k B$ (RANK) y su ligando (RANKL), son responsables de una osteoclastogénesis anormalmente intensa ${ }^{10,29}$.

La relación recíproca entre la inflamación y los traumatismos repetidos y no percibidos, en el contexto de la neuropatía sensorial, ha sido ampliamente señalada ${ }^{31}$. Sin embargo, estudios recientes demostraron que la pérdida de la propiocepción no es el único factor etiológico que conduce a la artropatía de $\operatorname{Charcot}^{33}$ y que la intervención de otros factores puede conducir a un aumento del flujo sanguíneo local.

Entre los factores etiológicos, el trauma es el más comúnmente encontrado en la patogénesis de la artropatía de Charcot y fue reportado en el 22 al $53 \%$ de los casos ${ }^{15,20,31}$.

La fuga capilar y posterior formación de edema es la respuesta fisiológica a un traumatismo cerrado ${ }^{37}$. A mayor energía del trauma, mayor perturbación del hueso trabecular que conduce a la acumulación de líquido intersticial y hemorragia en los espacios de la médula, es decir, a una contusión ósea. En un paciente neuropático, el pie no presenta dolor y la falta de la necesaria inmovilización gatilla y perpetua el ciclo inflamatorio ${ }^{38}$.

La osteomielitis y la cirugía pueden desencadenar una artropatía de Charcot en aquellos pacientes predispuestos ${ }^{39}$.

La artropatía de Charcot también se ha presentado luego un trasplante de riñón y páncreas simultáneo $(\mathrm{SPKT})^{41}$. En un estudio reciente y retrospectivo se encontró que seis pacientes $(4,6$
\%) fueron diagnosticados con artropatía de Charcot durante el primer año post trasplante donde las altas dosis de glucocorticoides fueron los principales factores asociados a la resorción ósea y a la proteólisis muscular ${ }^{41}$.

\section{Fisiopatología}

Existen dos teorías ampliamente respetadas y, si bien ninguna de ambas hipótesis puede por sí misma explicar completamente la patogénesis de la enfermedad conforme la investigación avanza, ni la teoría neurovascular que fue descripta por el propio Charcot ${ }^{43}$ ni la neurotraumática que fue apoyada principalmente por científicos alemanes, han perdido valor. Por el contrario, los avances en la comprensión de complejos procesos bioquímicos han entrelazado cada vez más los caminos de ambas hipótesis ${ }^{43,44}$.

Charcot describió la teoría neurovascular o neurotrófica ${ }^{45}$. Creía que la irritación de la "trófica" o centros nerviosos vasomotores causaba una alteración en la nutrición de los huesos y las articulaciones. Más aún, los partidarios de esta teoría sugieren actualmente que la neuropatía autonómica sería la responsable de la alteración del tono del músculo liso vascular de la pared arterial y que esto conduciría a un fallo en la vasorregulación y a un aumento en el flujo de sangre al hueso. En consecuencia, los monocitos y los osteoclastos invaden el sitio afectado y esto acelera la tasa de resorción ósea lo que resulta en osteopenia. La disminución de la resistencia estructural permitiría que traumas menores terminen en fracturas, dislocaciones y colapsos articulares ${ }^{43}$.

Volkman y Virchow confrontan esta teoría y sugieren que un pie insensible es propenso a sufrir traumas repetitivos no reconocidos ${ }^{45}$. Además de esto, la pérdida de la propiocepción causa una carga articular anormal. Los múltiples traumas y la inestabilidad resultan en el deterioro de la articulación.

Es de destacar que Chantelau et al. ${ }^{37}$ han utilizado resonancia magnética (RMN) para documentar el trauma óseo en las primeras etapas del pie de Charcot, lo que aporta evidencia sobre el papel fisiopatológico del trauma inadvertido.

La contribución de cada una de las teorías a la patogénesis de pie de Charcot se detalla ampliamente y se discute a continuación.

\section{Inflamación y neuropatía}

Actualmente se considera que la inflamación local es el factor indispensable que desencadena 
el curso de los acontecimientos en un ambiente de predisposición. Se postula que el balance entre las citoquinas proinflamatorias y las antiinflamatorias que conduce a una respuesta inflamatoria de magnitud adecuada se ve comprometido en los pacientes con $\mathrm{Charcot}^{47}$.

Esta incapacidad para controlar la intensidad y la duración de la respuesta inflamatoria local originaría un incremento en los niveles de TNF- $\alpha$ e IL-1 $\beta$ que, a su vez, llevaría a la mayor expresión de un polipéptido, el ligando del receptor activador del factor nuclear $\mathrm{kB}(\mathrm{RANKL})^{48}$. Este ligando es miembro de la súper familia TNF y activa el receptor activador del factor nuclear kB (RANK). La activación del RANK estimula las vías intracelulares que terminan en la activación del factor de transcripción nuclear kB (NF-kB). La expresión de NF-kB induce a las células precursoras de los osteoclastos a diferenciarse en osteoclastos maduros ${ }^{34,48}$.

El aumento de la actividad osteoclástica se manifiesta por un incremento de su capacidad de resorción ósea in vitro que es predominantemente, pero no exclusivamente, impulsada por RANKL ${ }^{29}$.

La actividad del RANKL es antagonizada por la osteoprotegerina (OPG), una glicoproteína soluble que actuando como receptor señuelo del RANKL, se une a éste y neutraliza sus efectos ${ }^{34}$.

En paralelo, el NF-kB aumenta la producción de osteoprotegerina de los osteoblastos $12,31,34,51$, que actúa como agente autolimitante de su función proinflamatoria. Los pacientes con artropatía de Charcot muestran una elevada relación RANKL/ OPG que favorece la progresión de la respuesta inflamatoria ${ }^{50}$ (Figura 1).

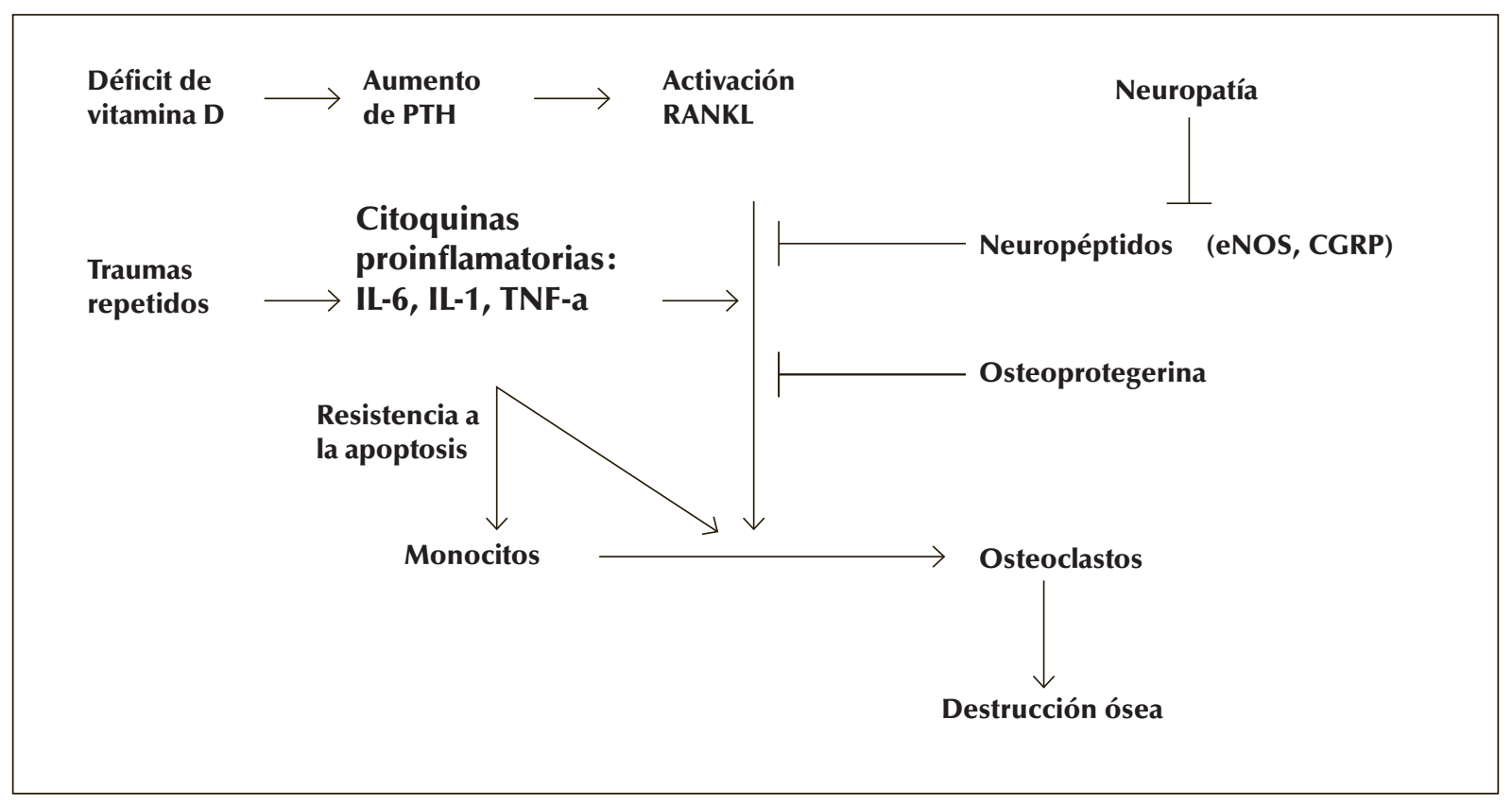

Figura 1: Vía receptor activador del factor nuclear $k B(R A N K L)$ en la fisiopatología en la fisiopatología de la neuroartropatía de Charcot. Tomado y modificado de: An overview of the Charcot foot pathophysiology. Diabetic Foot \& Ankle 4: 211-17, 2013.

Los osteoclastos juegan un papel clave en el curso de la artropatía de Charcot como células ejecutoras del desequilibrio en el recambio óseo que conduce a la osteólisis. La primera línea celular con evidencias de disfunción parece ser el monocito, célula precursora de los osteoclastos. Uccioli et al. analizaron el rol de los monocitos ${ }^{48}$ y encontraron que, en comparación con los pacientes diabéticos y con los sujetos sanos, los monocitos de los pacientes con Charcot agudo mostraron un fenotipo inmune proinflamatorio caracterizado por aumento de la producción de citoquinas proinflamatorias, reducción de la secreción de citoquinas antinflamatorias, incremento de la expresión de moléculas coestimuladoras de superficie y aumento de la resistencia a la apoptosis. Estas alteraciones pueden explicar, al menos en parte, la respuesta inflamatoria anormalmente intensa y prolongada que caracteriza a este trastorno.

Un creciente cuerpo de evidencia apoya actual- 
mente la posibilidad de que esta respuesta inflamatoria alterada juegue un papel patogénico fundamental en los cambios óseos y articulares que se desarrollan en esta enfermedad ${ }^{31}$. De hecho, el TNF- $\alpha$ y la IL-1 $\beta$, liberados durante el proceso inflamatorio, gatillan la mayor expresión de RANKL ${ }^{52,53}$. A menos que se activen, los monocitos se someten a la apoptosis.

La apoptosis representa un importante mecanismo homeostático que regula la duración y la intensidad de la inflamación. En este estudio ${ }^{48}$ hallaron que los monocitos de los pacientes con Charcot agudo fueron significativamente más resistentes a la apoptosis. Es posible que este aumento de la resistencia a la apoptosis pueda relacionarse con la mayor secreción de IL-1 $\beta$ y TNF- $\alpha$.

El péptido relacionado con el gen de la calcitonina (CGRP), es un péptido de 37 aminoácidos ampliamente distribuido en el sistema nervioso central y periférico, y sobre todo en los nervios sensoriales. Se ha demostrado que inhibe la producción de citoquinas proinflamatorias y aumenta la liberación de IL-10 por parte de los monocitos ${ }^{48}$. Por lo tanto, la reducción local del CGRP en el pie denervado del paciente con Charcot puede afectar la activación de los monocitos y generar un aumento de la producción de citoquinas proinflamatorias y reducción de la liberación de citoquinas antinflamatorias.

Finalmente algunos autores han señalado que una forma específica de neuropatía se requiere para desarrollar una NC, pero la literatura en este punto todavía es escasa ${ }^{55}$.

Young et al. ${ }^{10}$ han reportado neuropatía más grave en los pacientes con Charcot en comparación con los pacientes neuropáticos sin pie de Charcot. Sin embargo, el reciente consenso sobre Osteoartropatía de Charcot $^{11}$ no ha proporcionado más apoyo a la idea de que un tipo específico de neuropatía pueda ser responsable.

\section{Los neuropéptidos}

Se ha sospechado durante mucho tiempo que el sistema nervioso central interviene en la regulación y/o la modulación del metabolismo óseo. Esta función está mediada a través de péptidos que se sintetizan en las neuronas sensoriales amielínicas y son secretados a partir de su terminal periférico en el tejido óseo.

El papel esencial de los neuropéptidos en el metabolismo óseo fue profundamente estudiado por Offley et al. ${ }^{57}$. Ellos reportaron que la deple- ción, inducida por capcaisina, de neuropéptidos tales como sustancia $\mathrm{P}$ (SP) y el péptido relacionado con el gen de la calcitonina (CGRP) en las neuronas sensorial amielínicas de ratas adultas, resultó en un aumento de la pérdida de masa ósea y mayor fragilidad.

El CGRP es el neuropéptido más estudiado desde que la evidencia sugiere una acción directa de éste en la regulación de la actividad de los osteoblastos y en la reducción de la síntesis de RANKL ${ }^{12,34}$. El CGRP estimula la proliferación celular, la síntesis de citoquinas antiinflamatorias, la de factores de crecimiento y la síntesis de colágeno ${ }^{49}$. La mayor parte del CGRP presente en la circulación se libera a través de las terminales nerviosas sensoriales amielínicas tipo $\mathrm{C}$ y las pequeñas fibras mielínicas de tipo $\mathrm{Ad}^{56}$.

El pie denervado de los pacientes con Charcot se ve privado de la liberación de CGRP y, por lo tanto, una importante fuente de acción antiinflamatoria se ve comprometida ${ }^{48,58}$.

En otro estudio, La Fontaine et al. ${ }^{59}$ apoyan este concepto y sugieren, además, que las alteraciones en el CGRP y en la actividad de la sintasa de óxido nítrico endotelial (eNOS) pueden desempeñar un papel en el desarrollo del pie de Charcot.

El óxido nítrico (NO) es una molécula que funciona como segundo mensajero en muchas vías biológicas. Varios estudios sugieren que el NO tiene efecto sobre la modulación del metabolismo óseo. El efecto inhibidor del NO sobre los osteoclastos se demuestra en estudios con animales, donde se observó que puede inducir la apoptosis de pre-osteoclastos y disminuir la acción resortiva de los osteoclastos maduros en ratones ${ }^{60}$. En los pacientes con Charcot se detectó una menor expresión de la eNOS, lo que conduce a una menor síntesis de NO y menor supresión de la actividad de los osteoclastos ${ }^{59}$.

Más recientemente, Tan et al. estudiaron los efectos biomecánicos del flujo pulsátil de fluidos (PFF) a través de los canalículos del periostio61. Ellos demostraron que el PFF juega un papel importante en la prevención de la apoptosis de los osteocitos y que este efecto estaría mediado por el NO. Por otro lado, los osteoclastos son atraídos por los osteocitos apoptóticos, resultando en resorción ósea. Así los niveles disminuidos de NO, resultantes de una menor producción, pueden inducir la apoptosis de los osteocitos, aumentando indirectamente la función de los osteoclastos. 


\section{Estructura microvascular y recambio óseo}

Jeffcoate sugiere que la artropatía de Charcot requiere la coexistencia de una marcada neuropatía con una circulación periférica relativamente intacta ${ }^{38}$.

La rareza de la artropatía de Charcot podría explicarse por el hecho de que sólo afecta a las extremidades que conservan la capacidad de aumentar el flujo de sangre en respuesta a un determinado estímulo ${ }^{34}$.

Baker et al. estudiaron la tasa de máxima hiperemia microvascular ( $\mathrm{MMH}$ ) y encontraron que en los pacientes con Charcot, la MMH no sólo estaba relativamente preservada sino que era significativamente mayor que la de los pacientes con diabetes que sólo presentaban neuropatía ${ }^{63}$. Del mismo modo, Shapiro et al. demostraron un mayor flujo sanguíneo y capacidad de vasodilatación cutánea en los pacientes con $\mathrm{NC}^{64}$.

Estos hallazgos sugieren que los pacientes con Charcot conservan la capacidad de vasodilatación en oposición a pacientes con neuropatía diabética aislada, y podría ser una explicación de por qué no todos los pacientes con neuropatía diabética desarrollan Charcot.

La enfermedad arterial periférica parece tener un efecto protector en el desarrollo de la artropatía de Charcot $^{10}$. Esto probablemente se deba a la capacidad limitada de vasodilatación de las arterias afectadas.

La denervación simpática vascular aumenta el flujo local por medio de la apertura de shunts arteriovenosos, los cuales participan en la termorregulación en condiciones fisiológicas. La apertura de los shunts o derivaciones arterio-venosas aumenta la presión venosa e incrementa la filtración de fluido a través de fuga capilar ${ }^{10}$. Por consiguiente, aparece edema de tejidos profundos que aumenta la presión intracompartimental, comprimiendo la microcirculación y causando isquemia de los tejidos profundos ${ }^{66}$. Por otra parte, el extenso edema del tejido conectivo deteriora la resistencia a la tracción y la estabilidad de los tendones y ligamentos, lo que predispone a las subluxaciones y dislocaciones articulares.

En los pacientes con artropatía de Charcot, la exagerada actividad osteoclástica conduce a un desequilibrio con un constante proceso de remodelación. Sin embargo, en un estudio reciente, La Fontaine et al. sugirieron la posibilidad de una estructura anormal del hueso preexistente que podría predisponer a los pacientes diabéticos a desarrollar el pie de Charcot $^{30}$. Realizaron el examen histológico de muestras de tejido óseo de pacientes con diabetes y observaron una distorsión de la microestructura caracterizada por menor número de trabéculas y un menor número de células. Por lo tanto, los autores argumentaron que los cambios degenerativos en la microarquitectura del hueso no pueden ser una consecuencia, sino una causa de la artropatía de Charcot (Figura 2) ${ }^{30}$.

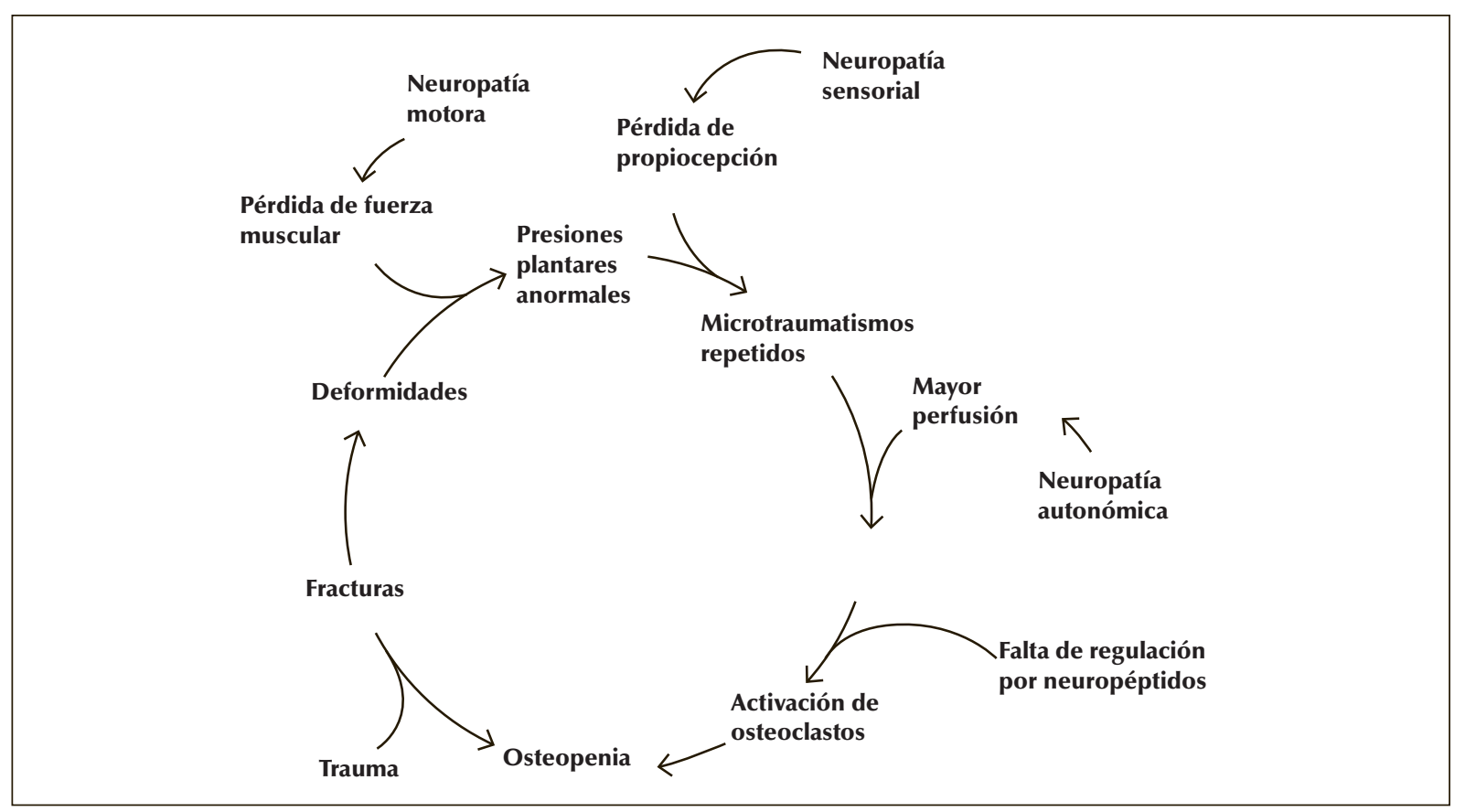

Figura 2: Ciclo fisiopatológico de la neuroartropatía de Charcot. Tomado y modificado de: An overview of the Charcot foot pathophysiology. Diabetic Foot \& Ankle 4: 211-17, 2013. 
Se ha observado una menor densidad mineral ósea (DMO) en pacientes con DM1 respecto de los pacientes con DM2, donde la DMO es similar o mayor a la de sujetos no diabéticos ${ }^{30}$.

Sobre este aspecto, Petrova et al. encontraron presentación a edades más tempranas y con mayor tiempo de diabetes en los pacientes diabéticos DM1 y reducción generalizada de la densidad mineral ósea en estos mismos pacientes, pero no en los DM2. Al mismo tiempo, los pacientes DM2 con Charcot presentaron neuropatía periférica más grave (percepción de la temperatura y percepción de la vibración) que sus pares DM1 (deterioro de la sensibilidad térmica, pero sensibilidad vibratoria conservada) ${ }^{68}$.

Por lo tanto, parecería que la teoría neurotraumática con una severa pérdida de sensación protectora y estrés mecánico asociado al soporte de peso en el contexto de la obesidad, podría ser mejor aplicada a la $\mathrm{DM} 2^{68}$. Y por el contrario, la teoría neurovascular con la resorción ósea pronunciada podría aplicarse más a la DM1, pero claramente se requiere mayor información en este ámbito ${ }^{68}$.

Se ha señalado que la deficiencia de vitamina D sería una condición preliminar para el desarrollo de la artropatía de Charcot $^{41}$ (Figura 1). Los valores de 1,25 (OH)2 D3 son significativamente menores en los pacientes diabéticos y esta disminución se traduce en una menor mineralización durante la formación ósea, una placa de crecimiento más pequeña y un inadecuado proceso de recambio óseo ${ }^{60}$ en un contexto de insulinopenia. Esto podría, en parte, explicar la menor DMO de los pacientes DM1.

\section{La hiperglucemia}

Se ha demostrado asociación entre la expresión de RANKL y las consecuencias metabólicas de la diabetes. El aumento de la glucemia potencia la formación de radicales libres, la hiperlipemia y la formación de productos finales de glicación avanzada (AGEs), lo que conduce a la activación del sistema RANK/RANKL ${ }^{31}$.

Se realizó un estudio que investigó la relación entre los receptores solubles de los productos finales de glicación avanzada (sRAGE) y los parámetros de la salud ósea en pacientes con neuroartropatía de Charcot $^{17}$. En este estudio, los valores de sRAGE en pacientes con Charcot se redujeron en un $86 \%$. La hiperglucemia genera aumento de AGEs, pero sin adecuados niveles de sRAGE para neutralizarlos; éstos tienden a acumularse en los tejidos de bajo recambio celular, como los tendones, la piel, los huesos, las placas amiloideas y cartílagos $^{75}$. La acumulación de AGE ha demostrado reducir la actividad osteoblástica vía RAGE, que a su vez aumenta la activación de RANKL y conduce a una mayor actividad osteoclástica y alteración de la mineralización de la matriz ósea ${ }^{74,76}$. Esta cascada predispone, en última instancia, a la fractura ósea.

Los autores proponen que la reducción de sRAGE en estos pacientes aumentaría la susceptibilidad de los osteoblastos a la apoptosis mediada por AGE, lo que limitaría su capacidad para reparar el hueso. Esto representa otra posible vía que une la neuroartropatía a la pérdida ósea, además de la vía de RANKL/osteoprotegerina.

Estos datos sugieren un fracaso de los mecanismos de defensa contra el estrés oxidativo en la diabetes y pueden predisponer a una menor integridad y fortaleza de los huesos.

La hiperglucemia altera la estructura de los tendones y ligamentos a través de la glicación no enzimática del colágeno. Este fenómeno podría causar acortamiento de los tendones y, por lo tanto, una redistribución anormal de las presiones plantares ${ }^{15}$. Por otra parte, ya que el colágeno es un componente estructural del hueso, las modificaciones relacionadas con la glicación del colágeno pueden alterar las propiedades mecánicas del hueso en sí, y predisponer a las fracturas y dislocaciones $^{60,71,77}$ (Figuras 1 y 2).

\section{Genética}

Los genes que regulan el eje OPG/RANK/ RANKL y sus polimorfismos ya se han implicado en la patogénesis de la osteoporosis ${ }^{78}$. Una correlación entre la artropatía de Charcot en pacientes diabéticos y determinados polimorfismos del gen OPG fue sugerida por primera vez por Pitocco et al. ${ }^{79}$ y posteriormente señalado por Korzon-Burakowska et al. ${ }^{80}$.

\section{Presentación clínica}

El diagnóstico inicial suele ser clínico. Es muy importante tener un alto índice de sospecha para realizar el diagnóstico precoz de neuroartropatía de Charcot, y esto debe ser seguido de una intervención temprana para prevenir las deformidades propias de esta patología ${ }^{13}$.

La secuencia de producción de esta enfermedad sería que a un trauma mínimo o a un esquince 
le sigue tumefacción acentuada del pie, en general indolora o levemente dolorosa. De forma equivocada se consideraba que la NC era una condición indolora, pero Brodsky encontró que el dolor estaba presente hasta en la mitad de los pacientes $7,26,81$. Además hay eritema con aumento de la temperatura local ${ }^{1,8}$. Habitualmente el paciente no presenta fiebre y el recuento de glóbulos blancos y la velocidad de eritrosedimentación son normales.

Los pulsos distales están presentes, todas las sensibilidades están ausentes, los reflejos aquilianos y rotulianos también y pueden haber lesiones tróficas de la piel con úlceras plantares e hiperqueratosis, generalmente por prominencia de las cabezas de los metatarsianos, asociadas a atrofia de los músculos interóseos ${ }^{26,83}$ y puede encontrarse cierto grado de hipermotilidad articular.

Una historia cuidadosa puede revelar un suceso traumático no reconocido.

La progresión de la neuroartropatía de Charcot, por lo general, sigue un patrón clínico y radiológico que fue descrito en la clasificación de Eichenholtz ${ }^{26}$. En ella se divide la artropatía en tres etapas: fragmentación, coalescencia y reconstructiva. En la práctica clínica, la fase inicial se considera un proceso destructivo y activo, mientras que las etapas de coalescencia y reconstructiva se postulan como un proceso reparador y crónico.

\section{Clasificaciones}

\section{Clasificación clínica}

Desde el punto de vista clínico, la progresión de esta patología se produce en dos fases: una fase aguda activa y otra de estabilización crónica. El proceso puede durar de 2 a 3 años ${ }^{84}$.

- Fase aguda: se observa inflamación aguda con eritema y edema unilateral, con aumento de aproximadamente $2^{\circ} \mathrm{C}$ de temperatura con respecto al otro pie, pudiendo la diferencia de temperatura ser de $10^{\circ} \mathrm{C}$. Incluye a pacientes que en estadio temprano no presentan cambios radiográficos y a aquellos que más tardíamente, presentan deformidad y cambios radiológicos (estadio agudo temprano y estadio agudo avanzado).

- Fase crónica: el aumento de la temperatura local del pie disminuye. El pie ya no se presenta caliente ni rojo, aunque puede persistir el edema. Aparecen grandes deformaciones, pierde la correcta arquitectura y se alteran los puntos de apoyo, lo que conducirá al desarrollo de lesiones de partes blandas. Se observa debilitamiento óseo, fragmentación, subluxación, dislocación y destrucción; el arco longitudinal del pie puede colapsar (Rocker-Botton) o producirse la subluxación del medio pie en el plano transverso (pie en "banana"). La subluxación de la articulación del tobillo puede dar una deformidad en varo o en valgus. Cuando el Charcot toma la parte posterior del pie, el pronóstico es más severo debido al alto riesgo de inestabilidad del tobillo y habrá una mayor necesidad de recurrir a amputaciones (Tabla 1).

\begin{tabular}{|c|c|c|}
\hline \multicolumn{3}{|c|}{$\begin{array}{l}\text { Tabla 1. Clasificación modificada de Eichenholtz: } \\
\text { neuroartropatía de Charcot }\end{array}$} \\
\hline Etapa & Hallazgos clínicos & Hallazgos radiológicos \\
\hline 0 & $\begin{array}{l}\text { Pérdida de sensibilidad, edema, } \\
\text { eritema, inestabilidad clínica }\end{array}$ & Normal \\
\hline I & $\begin{array}{l}\text { Edema, eritema, calor, aumento } \\
\text { de laxitud ligamentaria }\end{array}$ & $\begin{array}{l}\text { Osteopenia, fragmentación } \\
\text { periarticular, fractura, } \\
\text { subluxación }\end{array}$ \\
\hline II & $\begin{array}{l}\text { Disminución de calor e } \\
\text { inflamación local }\end{array}$ & $\begin{array}{l}\text { Absorción de las partículas } \\
\text { de Debris, fusión temprana y } \\
\text { esclerosis }\end{array}$ \\
\hline III & $\begin{array}{l}\text { Ausencia de inflamación, pie } \\
\text { estable }\end{array}$ & $\begin{array}{l}\text { Artrosis, osteolitos, esclerosis } \\
\text { subcondral }\end{array}$ \\
\hline
\end{tabular}

Tabla 1: Clasificación modificada de Eichenholtz de la Neuroartropatía de Charcot según los hallazgos clínicos y radiológicos. Tomado y modificado desde: Neuroartropatía de Charcot. Pie Diabético Digital 12:6-18, 2011.

La Etapa 0, también Ilamada "Charcot in situ" o “pre-etapa 1", no fue incluida en la descripción original realizada por Eichenholtz pero muchos autores la han reportado 7,81 .

\section{Clasificación anatómica}

La mayor parte de las lesiones ocurre en la articulación tarso-metatarsiana o articulación de Lisfranc, pero el antepié, el tobillo y la tuberosidad posterior del calcáneo también pueden ser sede de la enfermedad ${ }^{7,9}$.

Existen varias clasificaciones anatómicas en la literatura mundial, se mencionarán algunas de las más utilizadas.

La clasificación anatómica más frecuente fue propuesta por Sanders y Frykberg ${ }^{85}$, quienes describieron cinco patrones diferentes, según las zonas del pie que se encuentren afectadas.

En el patrón I (15\%) se ve afectada la parte delantera del pie [metatarsofalángica (MTF) y las articulaciones interfalángicas (IF)]; en el patrón II (40\%) las articulaciones tarso-metatarso (TMT); en el patrón III (30\%) las articulaciones involucradas son la naviculocuneiforme, talonavicular y calcaneocuboidea; en el patrón IV (10\%) el tobillo y articulaciones subastragalina, y en el patrón de $\mathrm{V}$ 
(5\%) se afecta el calcáneo ${ }^{15,22}$.

Una clasificación anatómica más simple distingue entre tres tipos de lesiones ${ }^{87}$ : lesión del antepié, que implica las articulaciones interfalángicas y MTF; lesión del medio pie, que involucra el TMT y las articulaciones del tarso; y la lesión del retropié, que incluye lesiones en la articulación del tobillo y el calcáneo. La parte media del pie es la zona más afectada $(60 \%)$.

Otra clasificación similar en tres tipos ha sido propuesta por Dounis.

Las clasificaciones anatómicas podrían ser clínicamente importantes ya que se han utilizado para predecir resultados, por ejemplo, las lesiones que afectan la parte delantera del pie parecen tener un mejor pronóstico que aquellas que involucran las articulaciones del retropié, dado que las lesiones del calcáneo puede tener efectos perjudiciales sobre la distribución del peso durante la marcha ${ }^{22}$.

Con el objetivo de guiar el tratamiento, Brodsky identificó un patrón de clasificación del colapso articular también basado en la localización anatómica (Figura 3) ${ }^{81}$.

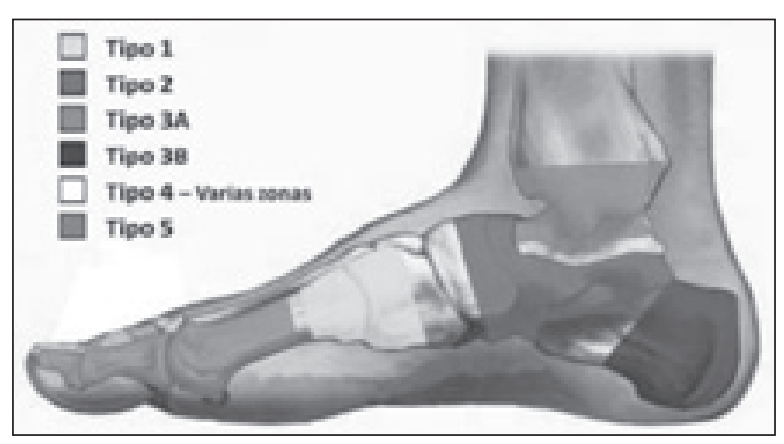

Figura 3: Clasificación anatómica de Brodsky del pie de Charcot. Tomado y modificado de: Neuroartropatía de Charcot. Pie Diabético Digital 12:6-18, 2011.

El tipo 1 ocurre en la articulación tarso-metatarsiana, localización más frecuente que corresponde al $60 \%$ de los casos aproximadamente, y cuyo compromiso a menudo conduce a una deformidad fija de un pie en balancín.

El tipo 2 afecta la articulación subtalar y la articulación de Chopart, ya sea individualmente o en conjunto, y corresponde al $10 \%$ de los casos.

El tipo 3A, indica el compromiso de la articulación del tobillo; es un $20 \%$ de los casos con deformidades tardías en varo o valgo, predisponiendo a úlceras recurrentes y osteomielitis que comprometen los maléolos.
En el tipo 3B, las deformidades se producen tras la fractura de la tuberosidad posterior del calcáneo, generando una migración proximal de la tuberosidad o deformidades tardías en la parte más distal del pie afectado $26,88,89$.

Posteriormente, este sistema de clasificación fue modificado por Trepman et al., quienes incluyeron los tipos 4 y 5: en el 4, múltiples áreas son afectadas, de forma simultánea o secuencial; mientras que en el tipo 5 la deformidad sólo involucra el antepié ${ }^{19}$ (Figura 3).

\section{Diagnóstico}

El diagnóstico de la NC se basa en una adecuada historia clínica y examen físico, apoyado por estudios complementarios ${ }^{15}$. Es muy importante tener un alto índice de sospecha y esto debe ser seguido de una intervención temprana para prevenir las deformidades propias de esta patología.

\section{Laboratorio}

Se han identificado altos niveles sanguíneos de marcadores óseos debido al aumento de la actividad osteoclástica. Ante la sospecha de osteoartropatía, se debe estudiar el metabolismo fosfocálcico, hidroprolina urinaria y fosfatasa alcalina ósea ${ }^{13}$.

Como regla general, los pacientes con NC sólo presentan signos de inflamación local, sin signos y síntomas sistémicos ${ }^{90}$, no presentan fiebre y el recuento de glóbulos blancos y la velocidad de eritrosedimentación son normales.

\section{Diagnóstico por imágenes}

\section{Radiología}

Es una herramienta primordial al momento de identificar las deformidades asociadas a la neuroartropatía de Charcot; cambios radiológicos en ausencia de herida o del antecedente de ésta, rara vez representan osteomielitis ya que la infección en la mayoría de los casos se produce por inoculación directa ${ }^{7,92}$.

Aunque en una etapa muy temprana de la NC las radiografías pueden dar falsos negativos, son un método de imagen disponible y barato que proporcionan gran información ${ }^{12}$. Por lo tanto, la herramienta inicial para el estudio de la NC sigue siendo la radiografía simple en tres direcciones: dorsoplantar con foco en antepié, lateral con apoyo monopódico y $3 / 4$ oblicua.

La descripción radiológica puede realizarse de acuerdo a las cinco D: densidad ósea, distensión 
articular, restos óseos (bony debris), desorganización articular y dislocación de la articulación ${ }^{18}$.

En concreto, las lesiones radiológicas del pie de Charcot pueden incluir8:

- Osteoporosis difusa.

- Subluxaciones y luxaciones visibles principalmente a nivel del escafoides o tarsometatarsianas.

- Osteólisis de las superficies óseas.

- Destrucción, fracturas espontáneas, telescopage de falanges o de los huesos del tarso.

- Signos de osteomielitis asociada.

Las características radiológicas de la parte delantera del pie incluyen: desmineralización, destrucción ósea y reacción perióstica, por lo que el diagnóstico diferencial con la osteomielitis suele ser difícil ${ }^{26}$. Además, la extremidad distal de los metatarsianos puede estar afinada por reabsorción ósea y tener aspecto de punta de lápiz y las falanges proximales pueden agrandarse y adquirir aspecto de copa o mortero, ${ }^{8,22}$, o presentar fragmentación de la cabeza de los metatarsianos ${ }^{15}$.

En la parte media del pie, se desarrolla fractura o luxación de la articulación de Lisfranc con la fragmentación ósea de las articulaciones TMT y colapso del arco longitudinal. Estos cambios en los rayos $X$ pueden ocurrir muy rápidamente (dentro de unas pocas semanas) $)^{15,94}$.

Por último, en la parte posterior del pie, pueden ocurrir los desplazamientos talocalcaneal con el colapso del astrágalo y las fracturas atípicas del calcáneo 22 .

En pacientes con neuroartropatía de larga duración, se observa una combinación de destrucción y neoformación ósea (esclerosis subcondral, osteofitos marginales) con bordes bien definidos.

\section{Gammagrafía ósea}

La gammagrafía ósea trifásica con uso de tecnecio-99m (Tc99) es muy sensible a la patología ósea activa. Sin embargo, la disminución de la circulación originaría exámenes falsos negativos y quizás más importante aún, la absorción no es específica para la $\mathrm{NC}^{12}$. La gammagrafía ósea con Tc99 en tres fases demuestra un aumento temprano en la captación ósea en todas las fases que ocurre por aumento del flujo ${ }^{22}$. Por lo tanto, el diagnóstico diferencial con la osteomielitis es difícil, ya que el aumento del recambio óseo caracteriza a ambas entidades ${ }^{8,19}$.

El barrido con células blancas marcadas (utilizando In 111) podría distinguir artropatía de Char- cot de infección ya que un scan de I-111 negativo generalmente excluye la infección, pero puede haber falsos negativos en pacientes inmunocomprometidos con osteomielitis leve ${ }^{8}$ y falsos positivos en articulaciones no infectadas ${ }^{15}$.

No existe una prueba diagnóstica definitiva para distinguir la NC de la osteomielitis, sin embargo la gammagrafía ósea de tres fases con tecnecio Tc-99m, seguida de un scan con leucocitos marcados con Indio In-111, ha demostrado una sensibilidad del 93 al $100 \%$ y una especificidad aproximada del $80 \%{ }^{19,22,9}$.

\section{Tomografía axial computada (TAC)}

LaTAC de alta resolución puede ser útil en dos situaciones: si se realizará una cirugía, sirve para brindar al cirujano una mejor idea de las estructuras óseas y el grado de fragmentación y, por otro lado, cuando otros estudios sugieren osteomielitis, la utilización de la TAC puede guiar una punción-biopsia ósea ${ }^{8}$.

\section{Resonancia magnética nuclear (RMN)}

Las imágenes por resonancia magnética nuclear (RMN) permiten la detección de cambios en las primeras etapas de la NC activa, cuando las radiografías todavía pueden ser negativas o normales. La RMN puede mostrar, con gran detalle, la anatomía y las patologías tanto de los tejidos blandos como del hueso.

La RMN tiene una alta sensibilidad y especificidad para la osteomielitis y se ha convertido en la prueba de elección para la evaluación de las complicaciones del pie diabético ${ }^{12}$.

La RMN no es específica ni conclusiva, sin embargo tiene utilidad para la detección de abscesos profundos y para plantear un diagnóstico diferencial con otras entidades como la osteopenia regional transitoria y el síndrome regional complejo ${ }^{81,88}$.

Para algunos autores es el segundo paso en el diagnóstico del pie con $\mathrm{NC}^{9}$. Las imágenes deben incluir T1 y (short tau inversión recovery, STIR) o secuencias T2 grasa saturadas.

La NC aguda se caracteriza por reducción de la intensidad de señal en secuencias T1 y el aumento de intensidad de señal en secuencia T2 ${ }^{15,26}$. La $\mathrm{NC}$ crónica se caracteriza por una señal con intensidad difusamente disminuida de médula ósea y la formación de quistes. La RMN es útil tanto para el diagnóstico diferencial con la osteomielitis, como para la detección de la osteomielitis superpuesta 
a una NC pre-existente ${ }^{15,26}$.

Tomografía por emisión de positrones (PET)

La tomografía por emisión de positrones (PET) con flúor-18 desoxiglucosa ha ganado terreno en el diagnóstico de esta entidad, especialmente cuando se combina con la tomografía computarizada (TC), lo que se ha denominado PET-TC. Esta asociación permite una localización más anatómica de la lesión, facilita la diferenciación porque demuestra captaciones de baja a mediana intensidad en la NC, a diferencia de las osteomielitis que típicamente son de más alta intensidad ${ }^{95,96 .}$

Permite la discriminación entre la infección de tejidos blandos y la osteomielitis, además de proporcionar una precisa localización anatómica ${ }^{97}$. La PET-TC es muy fiable para diferenciar la neuroartropatía de Charcot de la osteomielitis, sobre todo en aquellos casos en los que existe una úlcera, para los cuales se ha reportado una sensibilidad entre el 93,8 y el $100 \%$ 7,97.

\section{Densidad mineral ósea}

La DMO se ha relacionado con el patrón de lesión de la NC. De este modo, la luxación de la articulación es más frecuente en aquellos pacientes con mineralización normal, frente a las fracturas que son más comunes en los pacientes con disminución de la $\mathrm{DMO}^{98}$.

La decisión de imágenes nucleares contra RMN se basa en gran medida en las preferencias personales, la disponibilidad y la experiencia local. En general, si existe metal en el pie, se prefieren los exámenes de medicina nuclear, mientras que si se presenta con isquemia difusa o regional, la RMN es el examen preferido.

Recomendaciones para el diagnóstico de NC aguda ${ }^{12}$

- El diagnóstico de la NC aguda se basa principalmente en la historia clínica y el examen físico, pero debe ser confirmado por imágenes.

- La inflamación desempeña un papel clave en la fisiopatología del pie de Charcot y es el hallazgo clínico más temprano.

- La aparición de fracturas o luxaciones agudas del pie y/o tobillo en pacientes diabéticos con neuropatía debe ser considerada como Charcot agudo incluso en ausencia de deformidades.

- Las radiografías deben ser la imagen inicial y se deben buscar fracturas sutiles o subluxaciones.

- La RMN o imágenes nucleares puede confirmar las sospechas clínicas en presencia de radio- grafías normales.

Diagnóstico diferencial

La NC aguda debe ser diferenciada de otras condiciones que causan dolor e inflamación, como la celulitis, el trauma o un esguince, la gota aguda, trombosis venosa profunda y fundamentalmente la osteomielitis ${ }^{99}$.

El diagnóstico diferencial más importante es con las infecciones, es decir, la celulitis o la osteomielitis. Esto resulta más sencillo cuando no hay presencia o historia de ulceración del pie ${ }^{22}$.

Los signos y síntomas de infección sistémica son más probables que se encuentren en una infección que en la NC aguda, pero puede existir cierta superposición ${ }^{26,90}$.

Las técnicas de diagnósticos por imágenes son herramientas útiles para el diagnóstico diferencial de la NC. La RMN puede ser utilizada para diferenciar la NC aguda de la osteomielitis ${ }^{100}$. La osteomielitis presenta compromiso cortical y generalmente de un solo hueso, mientras que la NC aguda afecta a varias articulaciones y no afecta el hueso cortical ${ }^{15}$.

\section{Manejo y tratamiento}

El paso crucial en el manejo del pie de Charcot agudo es el diagnóstico correcto. El cuadro clínico clásico es un pie edematoso, eritematoso y caliente, con buenos pulsos pedios ${ }^{8}$.

El objetivo del tratamiento es evitar el trauma repetitivo en la zona afectada. Durante la fase aguda, la artropatía requiere rápidamente evitar el apoyo y el peso en el miembro afectado ${ }^{1}$ y disminuir el edema ${ }^{13}$. Para ello, puede ser de utilidad el uso de un yeso de contacto total o un walker (caminador). La ambulación debe ser gradual sin apoyo del pie afectado, usando muletas o andadores, y la progresión al apoyo y uso de calzado debe realizarse en forma cautelosa.

En los casos crónicos, donde las deformidades están instaladas, es necesario el uso de calzados ortopédicos específicos que permitan deambular al paciente, con descargas apropiadas de las zonas de hiperapoyo, para evitar las lesiones de partes blandas ${ }^{13}$.

Si el pie está infectado, por úlcera u osteomielitis, se hace tratamiento con antibióticos y si hay dolor se pueden usar antiinflamatorios no esteroides.

Se han utilizado alendronatos $u$ otros fijadores de calcio. Algunos autores observaron cambios significativos mientras que otros no ${ }^{4,11}$.

Hay acuerdo general que los resultados de 
intentos quirúrgicos para remodelar el pie son pobres y que deberían evitarse siempre que sea posible. Sin embargo, en casos cuidadosamente seleccionados, pueden ser útiles especialmente para lograr una buena alineación del pie y de esta manera evitar lesiones de partes blandas ${ }^{8}$.

El tratamiento quirúrgico se indica cuando el paciente presenta úlceras crónicas recurrentes e inestabilidad articular o desplazamientos por dislocación o fracturas ${ }^{13}$.

\section{Tratamiento médico}

El tratamiento médico de la NC está destinado a la descarga de los pies, el tratamiento de la enfermedad ósea y la prevención de nuevas fracturas ${ }^{102}$.

\section{Descarga}

La descarga del pie en la fase aguda de la NC es la estrategia de tratamiento más importante y podría detener la progresión de la deformidad. No existe un método estándar eficaz al 100\%, dado que el tratamiento depende de muchos factores, incluyendo el estadio clínico, la ubicación de la lesión, el grado de deformidad y las comorbilidades del paciente ${ }^{21,26}$.

En la fase I o de fragmentación, idealmente el pie debe ser inmovilizado con un yeso de contacto total (TCC), que se reemplaza inicialmente a los tres días, y a continuación cada una semana ${ }^{15}$. La reducción del edema suele ser notable en las primeras semanas de tratamiento. El yeso se debe cambiar con frecuencia para evitar el movimiento y el roce que se produce en la medida que el edema va disminuyendo ${ }^{15}$. Si es posible, el paciente debe utilizar muletas o silla de ruedas y debe ser alentado para evitar la carga de peso sobre el lado afectado. El yeso se mantiene hasta que haya desaparecido la inflamación, la temperatura del pie afectado no tenga una diferencia mayor de $2^{\circ} \mathrm{C}$ con el pie contralateral ${ }^{12}$ y presente evidencia radiográfica de resolución de la fragmentación ${ }^{15}$. Dado que la inmovilización puede durar de tres meses hasta más de un año cuando se afecta la parte posterior del pie y el tobillo ${ }^{26}$, existen diferentes alternativas al yeso de contacto total.

Un dispositivo alternativo para la descarga en la fase aguda es una bota de yeso removible prefabricada, que transforma una férula de marcha a una que se elimina con menos facilidad (iTCC) ${ }^{103,104}$ (Figura 4).

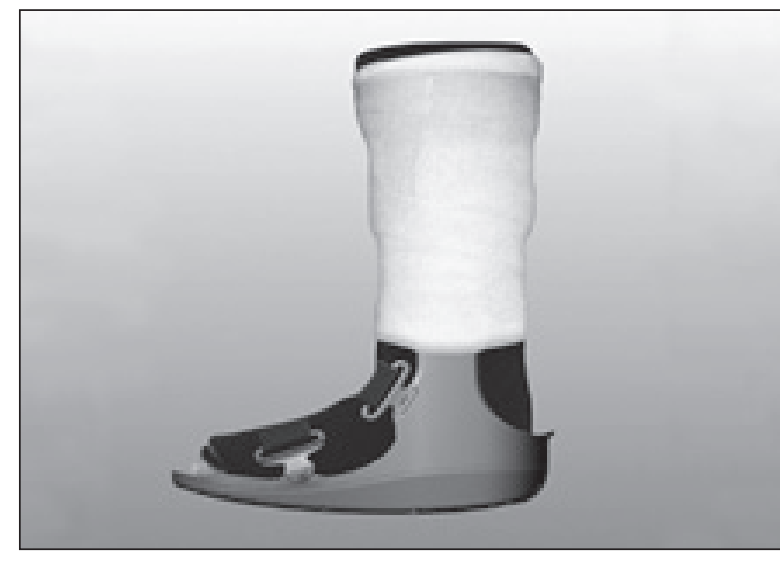

Figura 4: Instant Total Contact Cast (iTCC). Imagen tomada de: http://lowerextremityreview.com.

Otra alternativa más práctica es el Aircast Walker (Figura 5), un molde bivalvo, bordeado de cuatro células de aire que se inflan por una bomba de mano para asegurar un ajuste perfecto ${ }^{15}$.

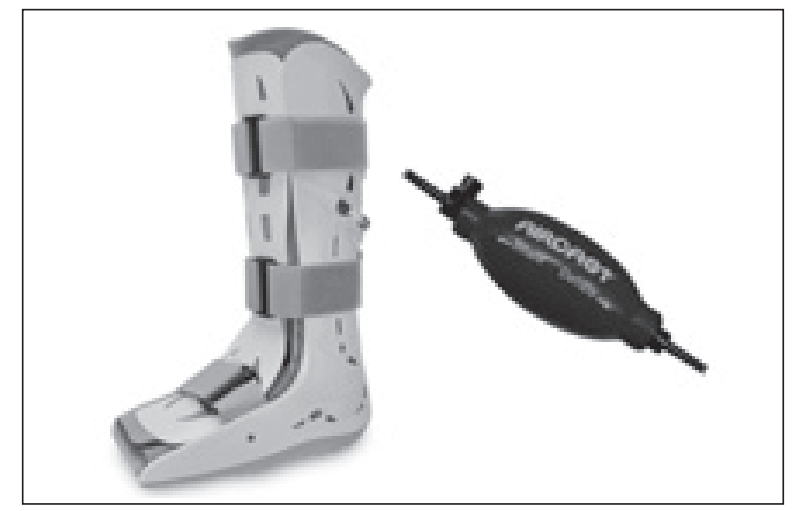

Figura 5: V. Aircast Walter. Imagen tomada de: Walker http://www.cascade-usa.com.

Otra opción de ortesis de descarga total es el Plastic Cast ${ }^{105}$ (Figura 6).

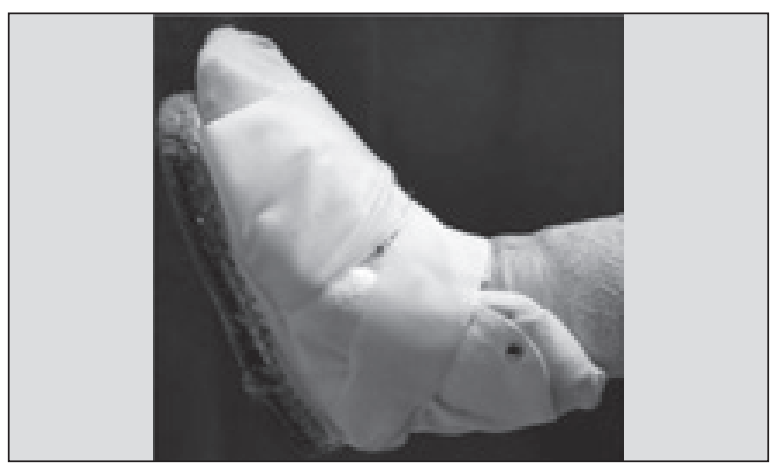

Figura 6: Plastic Cast. Imagen tomada de: Neuropatia de 
Charcot. Pie Diabético Digital 13:2-9, 2011.

La fase II o de coalescencia representa la etapa inicial de la curación, y en ella la hiperemia y el edema casi no están presentes. Es posible sustituir el yeso de contacto total o el dispositivo alternativo que se esté usando por un soporte plantar105 o por el Charcot Restraint Ortesis Walker $(\mathrm{CROW})^{15,106}$ (Figura 7). Este último es una órtesis de tobillo-pie de contacto total que se asemeja al yeso, pero es extraíble.

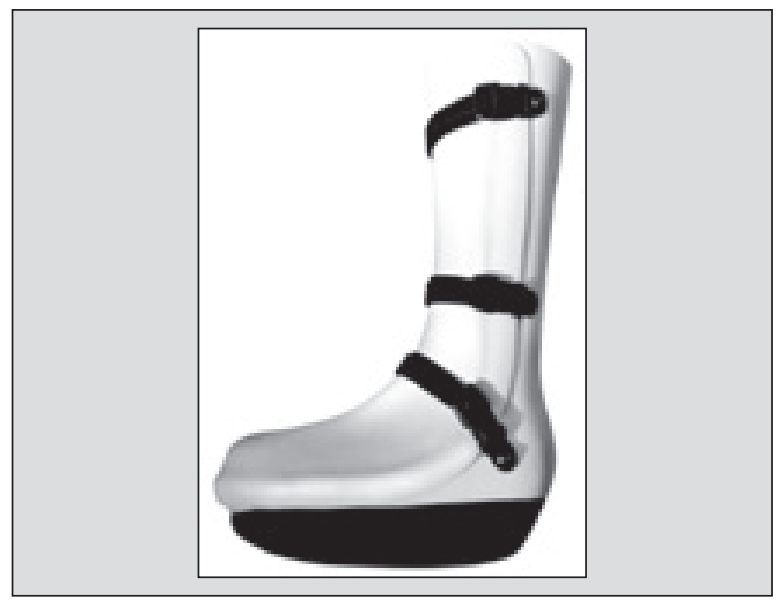

Figura 7: Charcot Restraint Ortesis Walker (CROW). Imagen tomada de: Utilization of advanced modalities in the management of diabetic Charcot neuroarthropathy. Am. J. Med. 6:1114-1120, 2010.

Para decidir el cambio del método de descarga, hay que conocer si el pie sigue con actividad o no. Para ello, se proponen dos técnicas. La más sencilla consiste en medir la temperatura cutánea de la zona afectada con un termómetro láser (único signo de inflamación cuantificable) y compararlo con el miembro contralateral (en el mismo lugar). Cuando la diferencia de temperatura entre ambos pies es menor o igual a $2{ }^{\circ} \mathrm{C}$, se podría interpretar como la finalización del período agudo. En caso contrario, habrá que repetir la medición al cabo de unas cuatro semanas, hasta que se normalice.

El otro método, más complejo y costoso, es la tomografía por emisión de positrones.

En fase III o de reconstrucción, los diferentes dispositivos pueden ser retirados y reemplazados por un soporte plantar combinado con el uso de calzado ortopédico. Este último debe estar diseñado para aliviar las zonas de alta presión, garantizar la estabilidad articular y dar cabida a las deformidades existentes, de modo que la carga de peso sea gradual sobre el pie afectado y no presente ningún riesgo de ulceración o reactivación ${ }^{19,20,26}$.

No hay que olvidar, además, el cuidado del pie contralateral para que no sufra una excesiva sobrecarga, debido a que también se encuentra afectado por la neuropatía y podría desencadenarse una lesión por hiperapoyo o un Charcot bilateral. La fractura contralateral puede ocurrir en casi el $80 \%$ de los $\operatorname{casos}^{14,19,26}$.

La duración y agresividad de la descarga (con o sin soporte de peso, no extraíble vs. extraíble) son guiadas por la evaluación clínica continua sobre la base del edema, eritema y cambios en la temperatura de la piel ${ }^{102}$. La evidencia de curación por radiografías o RMN fortalece la toma de decisiones clínicas para la transición del paciente hacia el uso de calzado ortopédico. Para evitar la posterior recurrencia o ulceración en la zona de deformidades, se recomienda el uso de diversos dispositivos luego de que un episodio agudo haya sido resuelto, incluyendo zapatos ortopédicos, botas, u otros apoyos que soportan peso. Se requiere la monitorización frecuente.

\section{Tratamiento antirresortivo}

Debido al excesivo recambio óseo que presentan los pacientes con NC aguda y a la acción inhibitoria sobre los osteoclastos que poseen los bifosfonatos, éstos han sido utilizados en diferentes estudios 20,107 .

Sin embargo, por el momento y mientras no se conozcan datos sobre una reducción en los tiempos de inmovilización, no hay indicación para el uso de los bisfosfonatos en el tratamiento rutinario de la $\mathrm{NC}^{9,20,107}$.

Del mismo modo, el uso de calcitonina y antinflamatorios no esteroides ha sido reportado como complemento al tratamiento convencional $22,26,107$.

Otra intervención potencial sería la utilización del ranelato de estroncio, que se emplea con éxito para el tratamiento de la osteoporosis ${ }^{9}$. La evidencia reciente ha demostrado que induce la expresión de osteoprotegerina (OPG) y suprime la expresión de RANKL en osteoblastos humanos ${ }^{110}$. Sin embargo, hasta la fecha, esta droga no se ha utilizado en el tratamiento de la fase aguda de la NC.

En los últimos años, nuevos agentes terapéuticos antiinflamatorios tales como los glucocorticoides, antagonistas de TNF- $\alpha$ (infliximab, etanercept) y antagonistas de RANK-L (Denosumab) se han propuesto para el tratamiento de la NC ${ }^{111}$. 


\section{Denosumab}

El denosumab es un anticuerpo monoclonal humano (lgG2) que se dirige y se une con gran afinidad y especificidad al RANKL impidiendo la activación de su receptor, RANK, en la superficie de los precur- sores de los osteoclastos y en los osteoclastos. Al impedir la interacción del RANKL/RANK se inhibe la formación, la función y la supervivencia de los osteoclastos y, de este modo, disminuye la resorción ósea y aumenta la masa y fuerza ósea tanto en el hueso cortical como el trabecular (Figura 8).

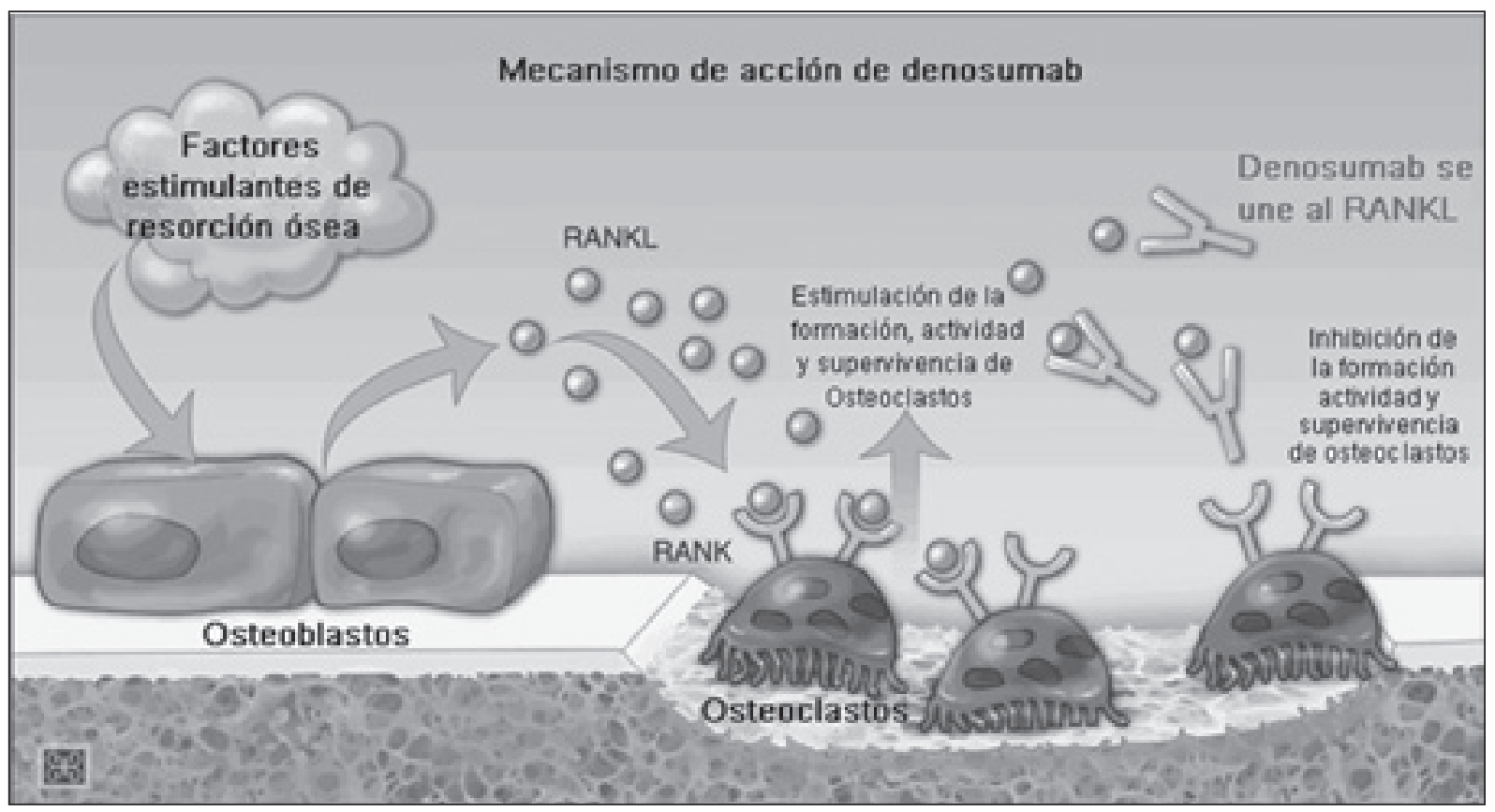

Figura 8: Mecanismo de acción de denosumab. Tomado y modificado de: Denosumab for the treatment of osteoporosis and cancer-related conditions. Clinical Pharmacology \&Therapeutics 91:123-133, 2012.

Una diferencia importante entre denosumab y los bisfosfonatos, es que éstos se integran a la matriz ósea, mientras que el denosumab no se incorpora en la estructura de hidroxiapatita. Por consiguiente, el efecto del denosumab es reversible cuando el tratamiento se interrumpe ${ }^{112}$.

La autorización para la comercialización de denosumab para el tratamiento de la osteoporosis en mujeres postmenopáusicas se basó en tres ensayos clínicos pivotales, comparativos directos de fase III en los que se evaluó la eficacia de denosumab: Estudio FREEDOM, Estudio DECIDE y el Estudio STAND. Por el momento, no hay ensayos clínicos con el uso de denosumab en NC aguda.

\section{Recomendaciones para la terapia médica}

- La descarga de los pies y la inmovilización son las recomendaciones de tratamiento más importantes en la NC aguda y pueden evitar una ma- yor destrucción.

- Hay poca evidencia para guiar el uso de terapias farmacológicas para promover la curación de NC

- Los soportes protectores son necesarios después de un episodio agudo, incluyendo los dispositivos que soportan peso, como zapatos moldeados, botas o aparatos ortopédicos.

- Se recomienda vigilancia de por vida para controlar la aparición de signos de recurrencia o nuevo episodio de NC, así como de otras complicaciones del pie diabético.

\section{Tratamiento quirúrgico}

El tratamiento quirúrgico de la neuroartropatía de Charcot de pie y tobillo se basa principalmente en la opinión de expertos y en series de casos retrospectivas, pequeñas y no controladas. El tratamiento quirúrgico debe ser considerado en los casos crónicos con inestabilidad articular o deformidad severa con fracaso del tratamiento conservador ${ }^{15,19,20}$. Generalmente, la cirugía se indica para resecar el hueso 
infectado (osteomielitis) y para la eliminación o corrección de las prominencias óseas y deformidades que no pueden ser adecuadamente tratadas con calzados terapéuticos $\mathrm{u}$ ortesis personalizadas ${ }^{113}$.

Los métodos de fijación utilizados habitualmente en pacientes sin Charcot han resultado inútiles en los pacientes con diabetes debido a la mala calidad del hueso, la mala vascularización y la glicación de los tejidos, llevando a fallas postoperatorias ${ }^{114}$.

La disección cuidadosa es de suma importancia en estos procedimientos, y en estos pacientes la anatomía de los tejidos blandos puede estar marcadamente perturbada. A menudo, los tendones permanecen unidos a sus respectivos sitios de unión, pero se tornan bastante laxos debido a la progresión de $\mathrm{NC}^{106}$.

Las intervenciones quirúrgicas clásicas incluyen:

- Exostectomía: generalmente utilizada cuando un paciente con una NC estable desarrolla prominencias óseas que conducen a la ulceración e infección recurrente ${ }^{15}$.

- Alargamiento del tendón de Aquiles: empleado cuando hay contractura del tendón de Aquiles que lleva a una distribución anormal de las presiones plantares ${ }^{115}$

- Artrodesis: usada cuando la deformidad no puede ser adecuadamente tratada con ortesis de descarga ${ }^{15}$.

Esto incluye técnicas de fijación interna que pueden realizarse como procedimiento único o por etapas. Las complicaciones incluyen infecciones profundas de la herida, úlceras recurrentes, uniones inestables o inadecuadas y fracturas ${ }^{19,117}$.

La fijación externa (procedimiento de una sola etapa) también se puede utilizar, especialmente cuando existe osteomielitis subyacente. Con esta técnica es poco frecuente la recurrencia de las úlceras ${ }^{118,121}$.

Y finalmente la amputación que lamentablemente puede ser inevitable cuando el tratamiento médico y quirúrgico han fracasado y el paciente presenta ulceración recurrente, infección o artrodesis inestable. Se ha informado que el 2,7\% anual de las deformidades por Charcot termina en amputación ${ }^{15}$.

Para conseguir reconstrucciones quirúrgicas exitosas en NC se plantean cuatro conceptos ${ }^{14}$. En primer lugar, con el fin de obtener una artrodesis con éxito, el sitio destinado para la fusión debe extenderse más allá de la zona de la lesión e incluir hueso no afectado y superficies articulares. En segundo lugar, la resección de hueso acorta la extremidad para permitir una disminución de la tensión en la envoltura de los tejidos blandos que rodean el área afectada. En tercer lugar, se debe utilizar la forma más fuerte de fijación que pueda ser tolerada por el tejido blando en cuestión. Y por último, el material protésico debe ser colocado en una posición de máxima función ${ }^{114}$. Comúnmente, la fijación externa se utiliza para proporcionar una mayor estabilidad luego de la reconstrucción de la extremidad inferior ${ }^{120}$ (Figura 9).

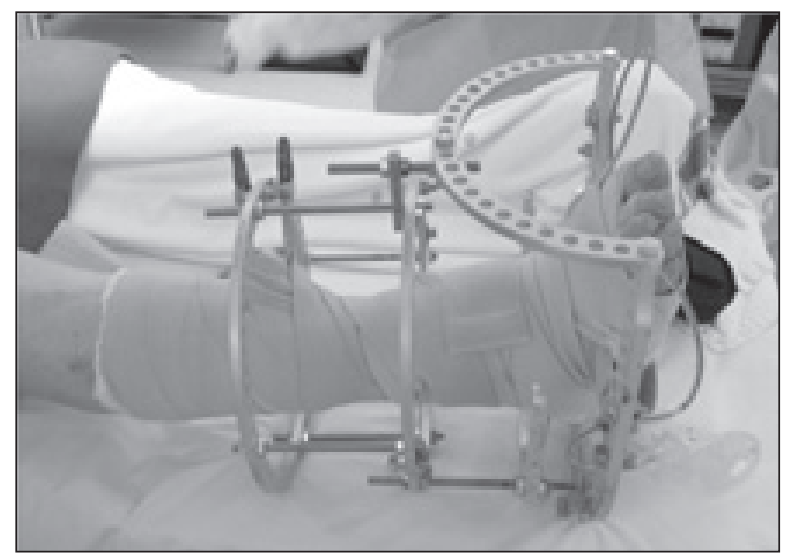

Figura 9: Dispositivo de fijación externa utilizado para proporcionar mayor estabilidad en la extremidad inferior posterior a una cirugía reconstructiva. Imagen tomada de: Utilization of advanced modalities in the management of diabetic Charcot Neuroarthropathy. Am. J. Med. 6:1114-1120, 2010.

Ha habido una tendencia creciente en la literatura sobre la indicación temprana del tratamiento quirúrgico para la corrección de las deformidades ${ }^{12,14}$. Más allá de los nuevos debates en este tema, un concepto universalmente aceptado es que la elección de un procedimiento quirúrgico, sea cual sea, debe resultar en un pie estable y plantígrado ${ }^{14}$.

Varios investigadores sugirieron que el alargamiento del tendón de Aquiles combinado con el yeso de contacto total tiene el potencial de disminuir las fuerzas de deformación en la parte media del pie y reducir la morbilidad asociada con la $\mathrm{NC}^{12}$. Por otro lado, la exostectomía ofrece la posibilidad de disminuir la presión causada por las prominencias óseas.

Históricamente la cirugía se ha evitado durante la fase inflamatoria activa debido al posible riesgo de infección de la herida o al fracaso de la fijación mecánica. Dos series de casos recientes reportaron resultados potencialmente favorables con la corrección temprana de las deformidades combi- 
nadas con artrodesis ${ }^{116,121}$

Las series con tratamientos quirúrgicos tempranos mostraron una mejora en la restauración de un pie plantígrado y en la prevención de la recurrencia de las úlceras, aunque la falta de unión y la pérdida de la corrección inicial fueron comunes ${ }^{12}$. El concepto de una fijación interna llamada superestructura, la cual se extiende más allá de la zona afectada, se ha desarrollado para hacer frente a estas cuestiones ${ }^{106}$.

\section{Artropatía de Charcot de tobillo}

Aunque la afectación de la parte trasera del pie y tobillo es mucho menos frecuente, presenta altas tasas de fracaso con el tratamiento no quirúrgico, por lo cual los miembros del grupo de trabajo ${ }^{12}$ reunidos en París en el año 2011, acordaron que el tratamiento quirúrgico podría considerarse un tratamiento primario. La corrección quirúrgica de la deformidad a nivel del tobillo es más probable que sea necesaria debido a la mala tolerancia a la deformidad en el plano coronal (es decir, varo o valgo del tobillo) y de las prominencias resultantes de los maléolos y su vulnerabilidad a la ulceración inducida por la presión.

\section{Recomendaciones para el tratamiento quirúrgico}

- El tratamiento quirúrgico es beneficioso en los casos refractarios a la descarga e inmovilización o en el caso de úlceras recurrentes.

- El tratamiento inicial de las fracturas y dislocaciones neuropáticas agudas no debe diferir del tratamiento de otras fracturas.

- La exostectomía es útil para aliviar la presión ósea que no se puede acomodar con medios de ortesis y prótesis.

- El alargamiento del tendón de Aquiles reduce la presión en la parte media del pie y mejora la alineación de la parte posterior con el tobillo y de la parte media con la parte anterior del mismo.

- La artrodesis puede ser útil en pacientes con inestabilidad, dolor o ulceraciones recurrentes con fracaso del tratamiento no quirúrgico, a pesar de una alta tasa de consolidación ósea incompleta.

- Para la NC severa del tobillo, el tratamiento quirúrgico puede considerarse un tratamiento primario.

\section{Bioadyuvantes en el tratamiento quirúrgico}

La compleja reconstrucción quirúrgica de la NC no está exenta de una alta tasa de complicaciones. La diabetes aumenta significativamente la incidencia de la falta de unión, retraso en la unión y de pseudoartrosis.

Con el fin de disminuir estas complicaciones, se ha propuesto la utilización de bioadyuvantes y agentes ortobiológicos para acelerar el proceso de curación ${ }^{129}$.

Los avances en agentes ortobiológicos incluyen: plasma rico en plaquetas (PRP), proteínas morfogénicas del hueso (Bone Morphogenic Proteins o BMPs) y matriz de hueso desmineralizado, entre otros.

El proceso de curación avanza a través de un predecible proceso de tres etapas: inflamación, proliferación y remodelación.

Las plaquetas desempeñan un papel crítico en la fase inflamatoria. Luego de ser inyectadas, forman un coágulo y 10 minutos después comienzan a secretar activamente los diferentes factores de crecimiento, liberándose más del 95\% de los factores de crecimiento presintetizados en el lapso de una hora.

Entre las proteínas secretadas por las plaquetas y que ejercen múltiples acciones sobre diferentes aspectos de la reparación tisular, se encuentran el factor de crecimiento transformante $\beta$ (FCT- $\beta$ transforming growth factor o TGF- $\beta$ ), factor de crecimiento tipo insulina (FCIL insulinlike growth factor o IGF) y factor de crecimiento derivado de las plaquetas (FCDP platelet derived growth factor o PDGF) ${ }^{130}$.

Algunas de las proteínas liberadas por las plaquetas se encuentran ausentes en heridas crónicas, lo cual aporta una evidencia más del papel de estas sustancias en la reparación tisular.

Una mayor concentración de estos tres críticos factores de crecimiento se puede lograr mediante la inyección de PRP en la zona de la injuria, en este caso, el área de la NC.

El plasma rico en plaquetas se define como una porción del plasma autólogo con una concentración plaquetaria superior a la basal obtenida mediante centrifugación ${ }^{131}$. Esta fracción plasmática contiene no sólo un mayor volumen de plaquetas sino también los factores responsables de la coagulación. La concentración plaquetaria obtenida se establece en torno a ocho veces la fisiológica.

Pinzur ${ }^{132}$ reportó en el año 2009, en pacientes con Charcot, una tasa de fusión del 91,3\% con la utilización de inyecciones de PRP. En este estudio, los pacientes eran de alto riesgo para la falta de unión debido a la presencia de infección, múltiples comorbilidades y obesidad.

La formación de hueso depende de la osteogé- 
nesis, osteoinducción y osteoconducción.

Las proteínas óseas morfogenéticas o bone morphogenetic proteins (BMPs) son proteínas osteoinductoras ${ }^{131}$ y factores de crecimiento que pertenecen a la familia de los factores de crecimiento transformantes TGF-beta (TGF- $\beta$ ), una súper familia de proteínas con la capacidad de inducir fuertemente la formación de hueso nuevo, cartílago y tejido conjuntivo. Las BMPs fueron descriptas por primera vez por Marshall Urist durante la formación de hueso de novo en ratas después de la implantación ${ }^{14}$. Al momento, son alrededor de 20 las BMPs identificadas; entre éstas, la BMP-2, la BMP-4, y la BMP-7 son las que parecen tener un papel más significativo en la formación ósea. Actualmente existen preparados comerciales que contienen BMP-2 y BMP-7133.

En el año 2000, la proteína osteogénica (OP)1 (BMP-7) fue aprobada como tratamiento para la falta de unión de huesos largos ${ }^{131}$. Las BMPs han sido utilizadas para las fusiones espinales como adyuvantes o sustitutos de injerto óseo. El desarrollo de las proteínas morfogenéticas óseas ofreció una alternativa al tradicional injerto óseo y ha sido el estándar de oro para la reconstrucción oral y maxilofacial (artículo maxilofacial)

En 2009, Schuberth et al. ${ }^{134}$ reportaron la utilización de la OP-1 en la reconstrucción de la NC con una tasa total de fusión del 84,21\%. Desde entonces ha sido empleada para la reconstrucción de la parte posterior del pie y fusiones de tobillo con buenos resultados.

La matriz ósea desmineralizada es a la vez un osteoinductivo y un osteoconductor, sustituto de injerto óseo que deriva de hueso cortical ${ }^{14}$. Se encuentra disponible en una variedad de formas, lo que la hace utilizable en muchos tipos de procedimientos quirúrgicos.

La matriz ósea desmineralizada se encuentra actualmente disponible en gel, masilla, pasta, polvo, virutas, granulados y otras formas.

Además de los agentes ortobiológicos, nuevos dispositivos de estimulación ósea han aparecido con el objetivo de facilitar la reconstrucción ósea en la NC. Actualmente hay tres tipos de dispositivos de estimulación ósea: de corriente continua, de acoplamiento capacitivo y de campo electromagnético pulsado. Los datos disponibles son insuficientes para poder seleccionar dispositivos implantables vs. no implantables ${ }^{14}$.

\section{CONCLUSIONES}

En la práctica diaria, los médicos debemos tener presente a la neuroartropatía de Charcot como un probable diagnóstico en todo paciente diabético con neuropatía que consulta por un pie rojo, caliente, hinchado y generalmente con escaso dolor. Actualmente, el diagnóstico sigue siendo clínico, pero puede confirmarse mediante la adecuada utilización de estudios de imágenes. Clínicamente se puede clasificar en una fase aguda y una crónica; otras clasificaciones se basan en la localización anatómica y en la historia natural de la enfermedad.

El proceso fisiopatológico que conduce a un episodio agudo de neuroartropatía de Charcot es un tema de investigación muy dinámico. En estudios recientes, muchos autores han enfatizado en la perturbación del ciclo inflamatorio en el núcleo de la fisiopatología del pie de Charcot. Tanto la teoría neurotraumática como la neurovascular participan y actualmente la fisiopatología del pie de Charcot puede ser descripta como el resultado de una compleja interacción entre factores predisponentes, incluyendo la presencia de diabetes, neuropatía y una circulación periférica intacta que proporciona la capacidad de montar una respuesta inflamatoria.

La progresión de la inflamación finalmente conduce a la lisis ósea, microfracturas y deformidad ósea, mediado por la vía RANK/RANKL, sin embargo una vía independiente mediada por citoquinas proinflamatorias también puede ser importante. El componente de la neuropatía (somático vs. autonómico) que predomina en cada caso en particular puede variar.

En este dilema, la neuropatía tiene otro contribuyente a través de la reducción de la secreción del CGRP en las neuronas lesionadas. Otros factores, incluyendo el emergente papel de los genes, pueden ser de importancia, mientras que la investigación adicional es bienvenida para determinar las potenciales diferencias entre DM1 y DM2.

En última instancia, la cascada de todos los cambios fisiopatológicos conducen al desarrollo del pie de Charcot y éste es el punto crítico en la historia natural.

Si se diagnostica de forma correcta y se realizan la inmovilización y descarga adecuadas, la inflamación local disminuye y la destrucción ósea -incluyendo la progresiva pérdida de la densidad mineral ósea- puede ser minimizada o evitada. Por el contrario, si el factor mecánico es sostenido, se 
perpetúa el proceso inflamatorio y puede dar lugar a la distensión y deformación de los ligamentos, fracturas y luxaciones de los huesos del pie con colapso y graves deformidades y/o inestabilidad articular. Las deformidades del pie de Charcot pueden complicarse con una ulceración que es con frecuencia difícil de sanar y con altas tasas de recurrencia. Además, tienen mayor riesgo de infección e incluso osteomielitis.

Tradicionalmente la cirugía se reserva para los casos crónicos con deformidad severa o inestabilidad de la articulación. Sin embargo, se debe tener en cuenta que los avances tecnológicos han permitido mejorar los resultados quirúrgicos con el mantenimiento de un pie plantígrado. Y es por este motivo que actualmente se propone que la cirugía puede ser útil tanto en las primeras etapas como en las etapas posteriores, cuando la descarga es ineficaz.

Además, el desarrollo de bioadjuvantes ortobiológicos contribuyó a mejorar el hueso y los resultados en materia de curación de heridas, clásico desafío en esta población de pacientes. Estos adelantos tecnológicos en su conjunto demostraron una mejora significativa en las tasas de preservación de los miembros.

Pese a lo expuesto, la pregunta que aún queda sin responder es: ¿por qué no todos los pacientes diabéticos con neuropatía desarrollan un pie de Charcot? Una explicación razonable a esta pregunta puede aclarar sustancialmente la patogénesis $y$, en consecuencia, ofrecer la posibilidad de evitar su aparición.

\section{REFERENCIAS}

1. Boulton A. J. M. The diabetic foot. An update. Foot Ankle Surg. 14:120-124, 2008.

2. Shojaie A, Esmaelzadeh M, Larijani B. Assessment and treatment of diabetic foot ulcer. Int. J. Clin. Pract. 61:1931-1938, 2007.

3. Crawford F, Mccowan C, Dimitrov BD, Woodburn J, Wylie GH, Booth E. The risk of foot ulceration in people with diabetes screened in community settings: findings from a cohort study. Q. J. Med. 1-8, 2010.

4. Bruges J, Márquez G, Macedo G, Ramos F, Valero K, Calvagno M, Schinca N, Gayoso R, Jubiz Y. Guías ALAD de Pie diabético XVIII (N²):73-86, 2010.

5. International Consensus Group on the Diabetic Foot and Practical Guidelines on the Management and the Prevention of the Diabetic Foot, Versions 1999, 2003, 2007. (www.idf.org/bookshop).

6. Boulton AJM, Armstrong D, Albert S et al. ADA-AACETask Force. Diabetes Care 31:1679-1685, 2008.

7. Botek G, Andreson M,Taylor R. Charcot neuroarthropathy: an often overlooked complication of diabetes. Cleveland Clinic Journal of Medicine 77:593-599, 2010.

8. Viñes G. Neuroartropatía o articulación de Charcot. Revista Nefrología Argentina 8:120-121, 2010.

9. Van Bon A. C. Charcot Neuro-Osteoarthropathy. Global Perspec- tive on Diabetic Foot Ulcerations, 14:271-278, 2011.

10. Young MJ, Marshall A, Adams JE, Selby PL, Boulton AJ. Osteopenia, neurological dysfunction, and the development of Charcot neuroarthropathy. Diabetes Care 18:34-8, 1995.

11. Tan AL, Greenstein A, Jarrett SR, Mc Gonagle D. Acute neuropathic joint disease: medical emergancy? Diabetes Care 28:2962-4, 2005.

12. Rogers LC, Frykberg RG, Armstrong DG, Boulton AJM, Edmonds M. The Charcot foot in diabetes. Diabetes Care 34:2123-9, 2011.

13. Neuroartropatía de Charcot. http://www.diabetes.org.ar/docs/7charcot.pdf.

14. Pappalardo J, Fitzgerald R. Utilization of advanced modalities in the management of diabetic Charcot neuroarthropathy. Am. J. Med. 6:1114-1120, 2010.

15. Gouveri E, Papanas N. Charcot osteoarthropathy in diabetes: a brief review with an emphasis on clinical practice. World J. Diabetes 2:59-65, 2011.

16. Mabilleau G, Edmonds ME. Role of neuropathy on fracture healing in Charcot neuro-osteoarthropathy. J. Musculoskelet Neuronal Interact. 10:84-91, 2010.

17. Witzke KA, Vinik Al, Grant LM et al. Loss of RAGE defense: a cause of Charcot neuroarthropathy? Diabetes Care 34:1617-1621, 2011.

18. Schoots IG, Slim FJ, Busch-Westbroek TE, Maas M. Neuro-osteoarthropathy of the foot-radiologist: friend or foe? Semin. Musculoskelet Radiol. 14:365-376, 2010.

19. Trepman E, Nihal A, Pinzur MS. Current topics review: Charcot neuroarthropathy of the foot and ankle. Foot Ankle Int. 26:4663, 2005.

20. Petrova NL, Edmonds ME. Charcot neuro-osteoarthropathycurrent standards. Diabetes Metab. Res. Rev 24:S58-S61, 2008.

21. Wukich DK, Sung W. Charcot arthropathy of the foot and ankle: modern concepts and management review. J. Diabetes Complications 23:409-426, 2009.

22. Rajbhandari SM, Jenkins RC, Davies C, Tesfaye S. Charcot neuroarthropathy in diabetes mellitus. Diabetologia 45:10851096, 2002.

23. Jeffcoate W, Lima J, Nobrega L.The Charcot foot. Diabet. Med. 17:253-258, 2000.

24. Armstrong DG, Todd WF, Lavely LA, Harkless LB, Bushman TR. The natural history of acute Charcot's arthropathy in a diabetic foot specialty clinic. Diabet. Med. 14:357-363, 1997.

25. Griffith J, Davies AM, Close CF, Nattrass M. Organized chaos? Computed tomographic evaluation of the neuropathic diabetic foot. Br. J. Radiol. 68:27-33, 1995.

26. Van der Ven A, Chapman CB, Bowker JH. Charcot neuroarthropathy of the foot and ankle. J. Am. Acad. Orthop. Surg. 17:562571, 2009.

27. Petrova NL, Foster AV, Edmonds ME. Difference in presentation of charcot osteoarthropathy in type 1 compared with type 2 diabetes. Diabetes Care 27:1235-1236, 2004.

28. Larson SA, Burns PR. The pathogenesis of Charcot neuroarthropathy: current concepts. Diabet Foot Ankle 3:122-36, 2012.

29. Mabilleau G, Petrova N, Edmonds M, Sabokbar A. Increased osteoclastic activity in acute Charcot's osteoarthropathy: the role of receptor activator of nuclear factor-kappa B ligand. Diabetologia 51:1035-40, 2008.

30. La Fontaine J, Shibuya N, Sampson HW, Valderrama P. Trabecular quality and cellular characteristics of normal, diabetic, and Charcot bone. J. Foot Ankle Surg. 50:648-53, 2011.

31. Jeffcoate WJ, Game F, Cavanagh PR. The role of proinflammatory cytokines in the cause of neuropathic osteoarthropathy (acute Charcot foot) in diabetes. Lancet 366:2058-2061, 2005.

32. Rostom S, Bahiri R, Mahfoud-Filali S, Hajjaj-Hassouni N. Neurogenic osteoarthropathy in leprosy. Clin. Rheumatol. 26:2153-5, 2007.

33. Chantelau E, Onvlee GJ. Charcot foot in diabetes: farewell to the 
neurotrophic theory. Horm. Metab. Res. 38:361-7, 2006.

34. Jeffcoate W. Charcot neuro-osteoarthropathy. Diabetes Metab. Res. Rev. 24:S62-5, 2008.

35. Jones KB, Mollano AV, Morcuende JA. Bone and brain: a review of neural, hormonal, and musculoskeletal connections. lowa Orthop J 24:123-32, 2004.

36. Tesfaye S, Stevens LK, Stephenson JM, Fuller JH. Prevalence of diabetic peripheral neuropathy and its relation to glycaemic control and potential risk factors: the EURODIAB IDDM complications study. Diabetologia 39:1377-84, 1996.

37. Chantelau E, Richter A, Schmidt-Grigoriadis P, Scherbaum WA. The diabetic Charcot foot: MRI discloses bone stres injury as trigger mechanism of neuroarthropathy. Exp. Clin. Endocrinol. Diabetes 114:118-23, 2006.

38. Jeffcoate WJ. Abnormalities of vasomotor regulation in the pathogenesis of the acute Charcot foot of diabetes mellitus. Int. J. Low Extrem. Wounds 4:133-7, 2005.

39. Ndip A, Jude EB, Whitehouse R, Prescott M, Boulton AJ. Charcot neuroarthrtopathy triggered by osteomyelitis and/or surgery. Diabet. Med. 25:1469-72, 2008.

40. Aragón Sánchez J, Lázaro Martínez JL, Hernández Herrero MJ. Triggering mechanisms of neuroarthropathy following conservative surgery for osteomyelitis. Diabet Med. 27:844-7, 2010.

41. Rangel ÉB, Sá JR, Gomes SA, Carvalho AB, Melaragno CS. Charcot neuroarthropathy after simultaneous pancreas_kidney transplant. Transplantation 94:642-5, 2012.

42. Jeffcoate W. The causes of the Charcot syndrome. Clin. Podiatr. Med. Surg. 25:29-42, 2008.

43. Chisholm KA, Gilchrist JM. The Charcot joint: a modern neurologic perspective. J Clin. Neuromusc. Dis. 13:1-13, 2011.

44. Slater RA, RamotY, Buchs A. The diabetic Charcot foot. Med. Assoc. J. 6:280-3, 2004.

45. Gökhan K, Olgar B, Mehmet G, Tahir Ö. An overview of the Charcot foot pathophysiology. Diabetic Foot \& Ankle 4: 211-17, 2013.

46. Papanas N, Maltezos E. Etiology, pathophysiology and classifications of the diabetic Charcot foot. Diabet Foot Ankle. 21:4-10, 2013.

47. Baumhauer JF, O'Keefe RJ, Schon LC, Pinzur MS. Cytokine induced osteoclastic bone resorption in Charcot arthropathy: an immunohistochemical study. Foot Ankle Int. 227:797-800, 2006.

48. Uccioli L, Sinistro A, Almerighi C, Ciaprini C. Proinflammatory modulation of the surface and cytokine phenotype of monocytes in patients with acute Charcot foot. Diabetes Care 33:350-5, 2010.

49. Wang L, Shi X, Zhao R, Halloran BP, Clark DJ. Calcitoningene-related peptide stimulates stromal cell osteogenic differentiation and inhibits RANKL induced NF-kappaB activation,osteoclastogenesis and bone resorption. Bone 46:1369-79, 2010.

50. Ndip A, Williams A, Jude EB, Serracino-Inglott F. The RANKL/ RANK/OPG signaling pathway mediates medial arterial calcification in diabetic charcot neuroarthropathy. Diabetes 60:218796, 2011.

51. Jeffcoate WJ. Theories concerning the pathogenesis of the acute Charcot foot suggest future therapy. Curr. Diab. Rep. 5:430-5, 2005.

52. Lam J, Abu-AmerY, Nelson CA, Fremont DH, Ross FP, Teitelbaum SL. Tumor necrosis factor superfamily cytokines and the pathogenesis of inflammatory osteolisis. Ann. Rheum. Dis. 62:ii82ii83, 2002.

53. Xu J, Wu HF, Ang ES, Yip K, Woloszyn M, Zheng MH, Tan RX. NF-k b modulators in osteolytic bone diseases. Cytokine Growth Factor Rev. 20:7-17, 2009.

54. Pitocco D, Ruotolo V, Caputo S, Mancini L, Collina CM. Sixmonth treatment with alendronate in acute Charcot neuroarthropathy: a randomized controlled trial. Diabetes Care 28:1214-5, 2005.

55. Stevens MJ, Edmonds ME, Foster AV, Watkins PJ. Selective neuropathy and preserved vascular responses in the diabetic Char- cot foot. Diabetologia. 35:148-54, 1992.

56. Imai S, Matsusue Y. Neuronal regulation of bone metabolism and anabolism: calcitonin gene-related peptide-, substance $\mathrm{P}$-, and tyrosine hydroxylase-containing nerves and the bone. Microsc. Res. Tech. 58:61-9, 2002.

57. Offley SC, Guo TZ, Wei T, Clark JD, Vogel H, Lindsey DP. Capsaicin-sensitive sensory neurons contribute to the maintenance of trabecular bone integrity. J. Bone Miner. 20:257-67, 2005.

58. Akopian A, Demulder A, Ouriaghli F, Corazza F, Fondu P, Bergmann P. Effects of CGRP on human osteoclast-like cell formation: a possible connection with the bone loss in neurological disorders? Peptides 21:559-64, 2000.

59. La Fontaine J, Harkless LB, Sylvia VL, Carnes D, Heim-Hall J, Jude E. Levels of endothelial nitric oxide synthase and calcitonin gene-related peptide in the Charcot foot: a pilot study. J. Foot Ankle Surg. 47:424-429, 2008.

60. Blakytny R, Spraul M, Jude EB. Review: the diabetic bone: a cellular and molecular perspective. Int. J. Low Extrem. Wounds 10:16-32, 2011.

61. Tan SD, Bakker AD, Semeins CM, Kuijpers-Jagtman AM, KleinNulend J. Inhibition of osteocyte apoptosis by fluid flow is mediated by nitric oxide. Biochem Biophys Res Comun 369:11504, 2008.

62. Nilforoushan D, Gramoun A, Glogauer M, Manolson MF. Nitric oxide enhances osteoclastogenesis possibly by mediating cell fusion. Nitric. Oxide 21:27-36, 2009.

63. Baker N, Green A, Krishnan S, Rayman G. Microvascular and Cfiber function in diabetic Charcot neuroarthropathy and diabetic peripheral neuropathy. Diabetes Care 30:3077-9, 2007.

64. Shapiro SA, Stansberry KB, Hill MA, Meyer MD. Normal blood flow response and vasomotion in the diabetic Charcot foot. J. Diabetes Complications 12:147-53, 1998.

65. Christensen TM, Simonsen L, Holstein PE, Svendsen OL, Bülow J. Sympathetic neuropathy in diabetes mellitus patients does not elicit Charcot osteoarthropathy. J Diabetes Complications 25:320-4, 2011.

66. Schaper NC, Huijberts M, Pickwell K. Neurovascular control and neurogenic inflammation in diabetes. Diabetes Metab. Res. 24:S40-4, 2008.

67. Christensen TM, Bülow J, Simonsen L, Holstein PE, Svendsen OL. Bone mineral density in diabetes mellitus patients with and without a Charcot foot. Clin Physiol. Funct. Imaging 30:130-4, 2010.

68. Petrova NL, Foster AV, Edmonds ME. Calcaneal bone mineral density in patients with Charcot neuropathic osteoarthropathy: differences between type 1 and type 2 diabetes. Diabet Med. 22:756-61, 2005.

69. Aljada A, Ghanim H, Saadeh R, Dandona P. Insulin inhibits NF-kB and MCP-1 expression in human aortic endothelial cells. J. Clin. Endocrinol. Metab. 86:450-3, 2001.

70. KatayamaY, Akatsu T, Yamamoto M, Kugai N, Nagata N. Role of nonenzymatic glycosylation of type I collagen in diabetic osteopenia. J. Bone Miner. Res. 1996;11:931-937.

71. Levin ME, Boisseau VC, Avioli LV. Effects of diabetes mellitus on bone mass in juvenile and adult-onset diabetes. N. Engl. J. Med. 294:241-245, 1976.

72. Kume S, Kato S, Yamagishi S y col. Advanced glycation endproducts attenuate human mesenchymal stem cells and prevent cognate differentiation into adipose tissue, cartilage, and bone. J. Bone Miner Res. 20:1647-1658, 2005.

73. Alikhani M, Alikhani Z, Boyd C y col. Advanced glycation end products stimulate osteoblast apoptosis via the MAP kinase and cytosolic apoptotic pathways. Bone 40:345-353, 2007.

74. Yaturu S. Diabetes and skeletal health. J. Diabetes 1:246-254, 2009.

75. Franke S, Siggelkow H, Wolf G, Hein G. Advanced glycation endproducts influence the mRNA expression of RAGE, RANKL and various osteoblastic genes in human osteoblasts. Arch. Physiol. 
Biochem.113:154-161, 2007.

76. McCarthy AD, Etcheverry SB, Bruzzone L, Lettieri G, Barrio DA, Cortizo AM. Non-enzymatic glycosylation of a type I collagen matrix: effects on osteoblastic development and oxidative stress.BMC Cell Biol. 2:16, 2001.

77. Viguet-Carrin S, Garnero P, Delmas PD. The role of collagen in bone strength. Osteoporos Int. 17:319-36, 2006.

78. Kim JG, Kim JH, Kim JY, Ku SY, Jee BC. Association between osteoprotegerin (OPG), receptor activator of nuclear factor kappa B (RANK), and RANK ligand (RANKL) gene polymorphisms and circulating OPG, soluble RANKL levels, and bone mineral density in korean postmenopausal women. Menopause 14:913-8, 2007.

79. Pitocco D, Zelano G, Gioffrè G, Di Stasio E, Zaccardi F. Association between osteoprotegerin G1181C and T245G polymorphisms and diabetic Charcot neuroarthropathy: a case-control study. Diabetes Care 32:1694-7, 2009.

80. Korzon-Burakowska A, Jako'bkiewicz-Banecka J, Fiedosiuk A, Petrova N. Osteoprotegerin gene polymorphism in diabetic Charcot neuroarthropathy. Diabet. Med. 29:771-5, 2012.

81. Asuncion J, Valcarcel P, Poggio D. Neuroartropatía de Charcot. Pie Diabético Digital 12:6-18, 2011.

82. Hordon LD, Goldberg DL, Nathan DM, Romain PL. Diabetic neuropathic arthropathy. Up to Date. 2010.

83. Stapleton JJ, Belezyk R, Zgonis T. Revisional Charcot neuroarthropathy of the foot and ankle. J. Am. Acad. Orthop. Surg. 26:127-39, 2009.

84. Gómez Vargas E, Pérez Hernández J. Características clínicas y radiológicas de 15 pacientes con osteoartropatía diabética. Revista de la Asociación Latinoamericana de Diabetes. XIII-N¹, 2005.

85. Batista F. Estadiamiento y tratamiento del pie de Charcot. Pie Diabético Digital 6:16-21, 2009.

86. Batista F, Monteiro AC. Tratamento cirúrgico da Neuroartropatía de Charcot: Apresentação de técnicas e resultados preliminares. Diabetes Clínica 7:358-366, 2005.

87. Giurini JM, Chrzan JS, Gibbons GW, Habershaw GM. Charcot's disease in diabetic patients. Correct diagnosis can prevent progressive deformity. Postgrad Med. 89:163-169, 1991.

88. MS. Pinzur. Current Concepts Review: Charcot arthropathy of the foot and ankle. Foot Ankle Int. 28:952-959, 2007.

89. JW Brodsky. The diabetic foot. In Coughlin MJ, Mann RA, Saltzman CL. Eds. Surgery of the Foot and Ankle. Philadelphia: Mosby Elsevier, 2007: 1333.

90. Petrova NL, Moniz C, Elias DA, Buxton-Thomas M, Bates M, Edmonds $\mathrm{ME}$. Is there a systemic inflammatory response in the acute charcot foot? Diabetes Care 30:997-998, 2007.

91. Akinci B, Yener S, Yesil S, Yapar N, Kucukyavas Y, Bayrakta. Acute phase reactants predict the risk of amputation in diabetic foot infection. J. Am. Podiatr. Med. Assoc. 101:1-6, 2011.

92. Robinson AHN, Pasapula C, Rodsky JW. Surgical aspects of the diabetic foot. J Bone Joint Surg Br. 91:1-7, 2009.

93. Sella EJ, Barrette C. Staging of Charcot neuroarthropathy along the medial column of the foot in the diabetic patient. J. Foot Ankle Surg. 38:34-40, 1999.

94. Gold RH, Tong DJ, Crim JR, Seeger LL. Imaging the diabetic foot. Skeletal Radiol. 24:563-571, 1995.

95. Keidar Z, Militianu D, Melamed E, Bar-Shalom R, Israel O. The diabetic foot: initial experience with 18F-FDG PET/CT.J Nucl. Med. 46:444-449, 2005.

96. Hopfner S, Krolak C, Kessler S, Tiling R. Preoperative imaging of Charcot neuroarthropathy. Does the additional application of 18F-FDG-PET make sense? Nuklearmedizin 45:15-20, 2005.

97. S. Heiba, D. Kolker, B. Mocherla, K. Kapoor, M. Jiang, H. The optimized evaluation of diabetic foot infection by dual isotope SPECT/CT imaging protocol. Foot Ankle Surg. 49:529-536, 2010.

98. Herbst SA, Jones KB, Saltzman CL. Pattern of diabetic neuropathic arthropathy associated with the peripheral bone mineral density. J. Bone Joint Surg. Br. 86:378-383, 2004.

99. Chantelau E. The perils of procrastination: effects of early vs. delayed detection and treatment of incipient Charcot fracture. Diabet. Med. 22:1707-1712, 2005.

100. Tan PL, Teh J. MRI of the diabetic foot: differentiation of infection from neuropathic change. Br. J. Radiol. 80:939-948, 2007.

101. Bem R, Jirkovska $Q$, Fejifarova $V$ et al. Itranasal calcitonin in the treatment of acute Charcot neuroosteoarthropathy: a randomised controlled trial. Diabetes Care 29:1392-1394, 2006.

102. Frykberg, R. G, \& Eneroth, M. Principles of conservative management. In: The Diabetic Charcot Foot: principles and management. Frykberg RG, Ed. Brooklandville, MD, Data Trace Publishing Company 93-116, 2010.

103. Armstrong DG, Lavery LA, Wu S, Boulton AJ. Evaluation of removable and irremovable cast walkers in the healing of diabetic foot wounds: a randomized controlled trial. Diabetes Care 28:551-554, 2005.

104. Armstrong DG, Short B, Espensen EH, Abu-Rumman PL, Nixon BP, Boulton AJ. Technique for fabrication of an "instant totalcontact cast" for treatment of neuropathic diabetic foot ulcers. J Am. Podiatr.Med. Assoc. 92:405-408, 2002.

105. Viade J, Perez J. C. Neuropatía de Charcot. Pie Diabético Digital 13:2-9, 2011.

106. Assal M, Stern R. Realignment and extended fusion with use of a medial column screw for midfoot deformities secondary to diabetic neuropathy. J. Bone Joint Surg. Am. 91:812-20, 2009.

107. Jude EB, Selby PL, Burgess J, Lilleystone P, Mawer EB, Page SR, Donohoe M, Foster AV, Edmonds ME, Boulton AJ. Bisphosphonates in the treatment of Charcot neuroarthropathy: a double-blind randomised controlled trial. Diabetologia 44:2032-2037, 2001.

108. Selby PL, Young MJ, Boulton AJ. Bisphosphonates: a new treatment for diabetic Charcot neuroarthropathy? Diabet. Med 11:28-31, 1994.

109. Anderson JJ, Woelffer KE, Holtzman JJ, Jacobs AM. Bisphosphonates for the treatment of Charcot neuroarthropathy. J. Foot Ankle Surg. 43:285-289, 2004.

110. Brennan TC, Rybchyn MS, Green W, Atwa S, Conigrave AD, Mason RS. Osteoblasts play key role in the mechanisms of action of strontium ranelate. British Journal of Pharmacology 2009; 157: 1291-1300.

111. Boulton AJ, Jeffcoate WJ, Jones TL, Ulbrecht JS. International collaborative research on Charcot's disease. Lancet 373:105106, 2009.

112. Denosumab. Sociedad Argentina de Endocrinología y Metabolismo. www.saem.org.ar/denosumab.asp.

113. Pinzur MS. Surgical management: history and general principles. In The Diabetic Charcot Foot: Principles and Management. DataTrace Publishing Company 165-188, 2010.

114. Sammarco VJ. Superconstructs in the treatment of Charcot foot deformity: plantar plating, locked plating, and axial screw fixation. Foot Ankle Clin. 14:393-407, 2009.

115. Holstein P, Lohmann M, Bitsch M, Jorgensen B. Achilles tendon lengthening, the panacea for plantar forefoot ulceration? Diabetes Metab. Res. 20:S37-40, 2004.

116. Simon SR, Tejwani SG, Wilson DL, SantnerTJ, Denniston NL. Arthrodesis as an early alternative to nonoperative management of charcot arthropathy of the diabetic foot. J. Bone Joint Surg. Am. 82:939-950, 2000.

117. Stefansky SA, Rosenblum BI.The Charcot foot: a clinical challenge. Int. J. Low Extrem. Wounds 4:183-187, 2005.

118. Pinzur MS. Neutral ring fixation for high-risk nonplantigrade Charcot midfoot deformity. Foot Ankle Int 28:961-966, 2007.

119. Conway JD. Charcot salvage of the foot and ankle using external fixation. Foot Ankle Clin. 13:157-173, 2008.

120. Jani MM, Ricci WM, Borrelli J Jr, Barrett SE, Johnson JE. A protocol for treatment of unstable ankle fracturing using transarticular fixation in patients with diabetes mellitus and loss of 
protective sensibility. Foot Ankle Int. 24:838-44, 2003.

121. Mittlmeier T, Klaue K, Haar P, Beck M. Should one consider primary surgical reconstruction in Charcot arthropathy of the feet? Clin. Orthop. Relat. Rev. 468:1002-1011, 2010.

122. Fabrin J, Larsen K, Holstein PE. Arthrodesis with external fixation in the unstable or misaligned Charcot ankle in patients with diabetes mellitus. Int. J Low Extrem. Wounds 6:102-107, 2007.

123. Wukich DK, Belczyk RJ, Burns PR, Frykberg RG. Complications encountered with circular ring fixation in persons with diabetes mellitus. Foot Ankle Int. 29:994-1000, 2008.

124. Bevilacqua NJ, Rogers LC. Surgical management of Charcot midfoot deformities. Clin. Podiatr. Med. Surg. 25:81-94, 2008.

125. Ayoub MA. Ankle fractures in diabetic neuropathic arthropathy: can tibiotalar arthrodesis salvage the limb?J Bone Joint Surg. Br. 90:906-914, 2008.

126. Dalla Paola L, Volpe A, Varotto D y col. Use of a retrograde nail for ankle arthrodesis in Charcot neuroarthropathy: a limb salvage procedure. Foot Ankle Int. 28:967-970, 2007.

127. Caravaggi $C$, Cimmino M, Caruso S, Dalla Noce S. Intramedullary compressive nail fixation for the treatment of severe Charcot deformity of the ankle and rear foot. J. Foot Ankle Surg. 45:20-24, 2006.

128. Pinzur MS, Noonan T. Ankle arthrodesis with a retrograde femoral nail for Charcot ankle arthropathy. Foot Ankle Int. 26:545549, 2005.

129. Grant WP, Jerlin EA, Pietrzak WS, Tam HS. The utilization of au- tologous growth factors for the facilitation of fusion in complex neuropathic fractures in the diabetic population. Clin. Podiatr. Med. Surg. 22:561-84, 2005.

130. Gandhi A, Bibbo C, Pinzur M, Lin SS. The role of platelet-rich plasma in foot and ankle surgery. Foot Ankle Clin. 10:621-37, 2005.

131. Liporace FA, Bibbo C, Azad V, Koerner J, Lin SS. Bioadjuvants for complex ankle and hindfoot reconstruction. Foot Ankle Clin. 12:75-106, 2007.

132. Pinzur MS. Use of platelet-rich concentrate and bone marrow aspirate in high-risk patients with Charcot arthropathy of the foot. Foot Ankle Int. 30:124-7, 2009.

133. Lieberman JR, Daluiski A, EinhornTA. The role of growth factors in the repair of bone. Biology and clinical applications. J. Bone Joint Surg. Am. 84:1032-44, 2002.

134. Schuberth JM, Di Domenico LA, Mendicino RW. The utility and effectiveness of bone morphogenetic protein in foot and ankle surgery. J. Foot Ankle Surg. 48:309-14, 2009.

135. Guerkov HH, Lohmann CH, Liu Y, Dean DD, Simon BJ, Heckman JD, Schwartz Z, Boyan BD. Pulsed electromagnetic fields increase growth factor release by nonunion cells. Clin. Orthop. Relat. Res. 384:265-79, 2001.

136. Brighton CT, Wang W, Seldes R, Zhang G, Pollack SR. Signal transduction in electrically stimulated bone cells. J. Bone Joint Surg. Am. 83:1514-23, 2001.

137. Hockenbury RT, Gruttadauria M, McKinney I. Use of implantable bone growth stimulation in Charcot ankle arthrodesis. Foot Ankle Int. 28:971-6, 2007.

\section{Fe de erratas}

- El artículo "Detección de neuropatía autonómica cardíaca con maniobras de baja complejidad en atención ambulatoria", publicado en el Volumen 48, $N^{\circ}$ 1, marzo de 2014 (páginas 5-10), fue realizado en el contexto de la Carrera de Especialista en Nutrición de la Universidad Barceló.
- En el artículo "Manifestaciones dermatológicas asociadas a diabetes mellitus", publicado en el Volumen 48, № 1, marzo de 2014, en la página 34, donde dice: " $\mathrm{C}$ ) gangrena (imagen tomada del Ateneo Bibliográfico de Pie Diabético. Escuela de Graduados de la SAD)," debió decir: "C) gangrena (imagen provista por la Dra. Marta Calvagno para la presentación de un caso clínico durante el Ateneo Clínico de Pie Diabético de la Escuela de Graduados de la SAD, 2013)". 